\title{
Microscale Rearrangement of Ammonium Induced by Snow Metamorphism
}

\author{
Jürg C. Trachsel1,2, Sven E. Avak ${ }^{3,4,5}$, Jacinta Edebeli2,5, Martin Schneebeli1, \\ Thorsten Bartels-Rausch ${ }^{5 *}$, Sabina Bruetsch ${ }^{5}$ and Anja Eichler ${ }^{4,5 *}$ \\ ${ }^{1}$ WSL Institute for Snow and Avalanche Research SLF, Davos, Switzerland, ${ }^{2}$ Department of Environmental Systems \\ Science, ETH Zurich, Zurich, Switzerland, ${ }^{3}$ Department of Chemistry and Biochemistry, University of Bern, Bern, \\ Switzerland, ${ }^{4}$ Oeschger Centre for Climate Change Research, University of Bern, Bern, Switzerland, ${ }^{5}$ Laboratory \\ of Environmental Chemistry, Paul Scherrer Institute, Villigen, Switzerland
}

\section{OPEN ACCESS}

Edited by:

Maurine Montagnat,

Centre National de la Recherche Scientifique (CNRS), France

Reviewed by:

Florent Domine

Laval University, Canada

Tara Kahan,

University of Saskatchewan, Canada

*Correspondence:

Anja Eichler

anja.eichler@psi.ch

Thorsten Bartels-Rausch thorsten.bartels-rausch@psi.ch

Specialty section: This article was submitted to

Cryospheric Sciences,

a section of the journal

Frontiers in Earth Science

Received: 28 January 2019

Accepted: 11 July 2019

Published: 07 August 2019

Citation:

Trachsel JC, Avak SE, Edebeli J, Schneebeli M, Bartels-Rausch T, Bruetsch S and Eichler A (2019)

Microscale Rearrangement of Ammonium Induced by Snow Metamorphism

Front. Earth Sci. 7:194. doi: 10.3389/feart.2019.00194
Earth's snowpack hosts chemical impurities that exchange with the overlying air, strongly impacting atmospheric chemistry. Being embedded in firn and glacier ice formed from surface snow, impurities provide the basis for reconstructing past atmospheric composition from ice core records. The location of these impurity compounds within the snow critically controls their reactivity and preservation. Ammonium $\left(\mathrm{NH}_{4}{ }^{+}\right)$determines acid-base equilibria and buffer capacity within the snow and is a fundamental icecore proxy, especially for biogenic, forest fire, and anthropogenic emissions. However, the redistribution during snow metamorphism affecting snow chemical reactivity and potential post-depositional relocation is not understood so far. Here, we study the rearrangement of $\mathrm{NH}_{4}{ }^{+}$and five other major ions $\left(\mathrm{Ca}^{2+}, \mathrm{Cl}^{-}, \mathrm{F}^{-}, \mathrm{Na}^{+}\right.$, and $\left.\mathrm{SO}_{4}{ }^{2-}\right)$ during dry snow metamorphism using a series of elution experiments. Artificial and natural snow samples were stored for up to 3 months at a controlled temperature gradient of $40 \mathrm{~K} / \mathrm{m}$ and isothermal conditions. The different types of snow increase complexity as natural and artificial snow have a different history that impacts their physical properties and the initial distribution of impurities. Further, we test our findings using natural snow samples taken from different depths of a natural snowpack at the Weissfluhjoch (Swiss Alps) to confirm the impact of our laboratory results to the cryosphere. With progressing temperature gradient metamorphism, snow structures in natural and artificial snow converged and ions with high solubility in ice $\left(\mathrm{NH}_{4}{ }^{+}, \mathrm{F}^{-}\right.$, and $\mathrm{Cl}^{-}$) were incorporated into the less accessible ice interior. In contrast, ions with lower solubility $\left(\mathrm{Ca}^{2+}, \mathrm{SO}_{4}{ }^{2-}\right.$, and $\left.\mathrm{Na}^{+}\right)$became better accessible for the eluent. Our results show that the redistribution during snow metamorphism is strongly dependent on the temperature gradient, exposure time and chemical composition. This study allowed for the first time to explicitly relate the general low relocation proneness of $\mathrm{NH}_{4}+$ during post-depositional processes such as meltwater percolation to the preferred incorporation of this ion into the less accessible ice interior during snow metamorphism. Furthermore, our results imply that with ongoing aging of a snowpack, $\mathrm{NH}_{4}{ }^{+}$, independent of its primary location, is less available for chemical reactions at the air-ice interface.

Keywords: snow re-crystallization, temperature gradient, ammonium, major ions, elution, impurity location, redistribution, ice structure 


\section{INTRODUCTION}

Ice cores recovered from cold glaciers are invaluable archives of past climate and atmospheric composition, covering up to 800,000 years (Members Epica Community, 2004). Among the various types of impurities trapped in the ice, major ions provide information about past changes in anthropogenic pollution, atmospheric transport, forest fires, and atmospheric temperature (Legrand and Mayewski, 1997; Kaspari et al., 2007; Kellerhals et al., 2010; Eichler et al., 2011; Thompson et al., 2013). During snowfall, atmospheric constituents such as aerosol particles and gases are scavenged and deposited by wet and/or dry deposition. After deposition in polar or high-altitude regions, snow is successively transformed into firn and glacier ice, leading to an embedding of chemical impurities including major ions. However, the ice-core concentration records of major ions are not only determined by their initial atmospheric concentrations. Post-depositional processes can strongly alter the originally deposited signal. Such processes include wind erosion (Lorius et al., 1969; Dansgaard et al., 1973), re-emission of volatile compounds from the snow surface (Lalonde et al., 2002; Röthlisberger et al., 2002; Bartels-Rausch et al., 2008), sublimation (Stichler et al., 2001), migration within the snow and firn layer (Saltzman, 1995; Wolff, 1996), and relocation during melt-water percolation (Eichler et al., 2001; Li et al., 2006; Grannas et al., 2013). With increasing global temperatures, the fate of impurities during melt events is of increasing concern (Eichler et al., 2001; Meyer and Wania, 2008; Grannas et al., 2013). Species embedded in the interior of the snow matrix are less prone to being washed away by melt or rainwater than those species located at the air-ice interface. Eichler et al. (2001) have shown that in sections of ice core records that had experienced melt processes traces of impurities with high solubility in ice can still reliably be used as archives to reconstruct past atmospheric composition.

Further interest in the location of impurities comes from their role in chemistry. Snow is a fully connected porous ice structure and readily exchanges trace gases and aerosols with the overlying air (Dominé and Shepson, 2002; Grannas et al., 2007; BartelsRausch et al., 2014). These fluxes are an interplay of physical exchange processes and chemistry. The chemical complexity of snow with its multiphase and multicomponent character has recently raised much interest (Abbatt et al., 2012; Bartels-Rausch et al., 2014; Kahan et al., 2014). Laboratory and field studies have shown that fluxes originate from impurities hosted in various compartments of snow. Volatile impurities forming a solid solution may portioning to the gas phase, as shown for formaldehyde (Barret et al., 2011a,b). Surface adsorption and related fluxes from and to the air-ice interface is of high relevance for halogens, whereas contributions from their solid solution are thought to be negligible (Abbatt et al., 2012). Similar, the rate of higher-order chemical reactions critical depends on the location with significant differences for reactions occurring at the airice interface compared to those in liquid fractions of the snow, such as brine (Bartels-Rausch et al., 2014) or aerosol deposits (Koop et al., 2000; Bartels-Rausch et al., 2014). Chemistry in solid solutions is generally negligible. That the chemistry critically depends on the origin of impurities and the chemical properties of these compartments rather than simply the total impurity concentrations was recently impressively illustrated by a field study on halogen chemistry in arctic snow (Pratt et al., 2013).

While it is clear that the fate of impurities and thus their preservation in ice cores and their role in atmospheric chemistry, critical depends on their location - in particular, the distribution between solid solution, liquid fraction, and at the air-ice interface- the role of snow dynamics on this distribution is essentially open. Dry metamorphism is the most common dynamic process of snow "aging." Snow on Earth's ground is almost always exposed to a temperature gradient, for example between bedrock and the overlying air. Consequently, the relatively warmer ice surface sublimates and the water vapor is deposited on the cold side of the structure. Studies of snow exposed to a temperature gradient have shown that dry metamorphism leads to complete restructuring of the snowpack, i.e., to a mass turnover of the entire ice mass of up to $60 \%$ per day at a gradient of $\sim 50 \mathrm{~K} / \mathrm{m}$ (Pinzer and Schneebeli, 2009; Pinzer et al., 2012). Although physical changes during snow metamorphism are well studied, very little is known about concurrent rearrangement of chemical species. Hewitt et al. (1991) investigated the effect of snow metamorphism on the redistribution of $\mathrm{Cl}^{-}, \mathrm{NO}_{3}{ }^{-}$, and $\mathrm{SO}_{4}{ }^{2-}$. This study suggested incorporation of $\mathrm{Cl}^{-}$and $\mathrm{NO}_{3}{ }^{-}$into the ice interior and exclusion of $\mathrm{SO}_{4}{ }^{2-}$ to the air-ice interface with progressing snow metamorphism. Motivation to study the incorporation of ions during metamorphism came from its influence on ionic concentrations in meltwater, where excluded ions lead to ionic pulses early in the melt with potentially adverse impacts on the environmental systems.

Of the major ions in ice cores, $\mathrm{NH}_{4}{ }^{+}$is an essential proxy for biogenic, forest fire, and anthropogenic agricultural emissions (Döscher et al., 1996; Fuhrer et al., 1996; Eichler et al., 2009, 2011; Kellerhals et al., 2010). $\mathrm{NH}_{4}{ }^{+}$is widely used to date ice cores by counting annual layers due to the strong seasonal variability (Fuhrer et al., 1993). The majority of previous studies point to good preservation of $\mathrm{NH}_{4}{ }^{+}$concentration records even in areas strongly affected by melting (Alps (Eichler et al., 2001), South America (Ginot et al., 2010), Tian Shan (Li et al., 2006), and Svalbard (Virkkunen et al., 2007). The good preservation has been suggested to be due to rearrangement processes during snow metamorphism, including a burial of $\mathrm{NH}_{4}{ }^{+}$into the ice matrix, not accessible by meltwater. To the best of our knowledge, no studies on the relocation of ammonium $\left(\mathrm{NH}_{4}{ }^{+}\right)$during snow metamorphism are available, so far. Further interest is motivated by $\mathrm{NH}_{3}$ being the most abundant alkaline gas in the atmosphere. Consequently, $\mathrm{NH}_{3} / \mathrm{NH}_{4}{ }^{+}$concentrations in the air and snow strongly impact the uptake of acidic species into ice (Hoog et al., 2007). Therefore, relocation of $\mathrm{NH}_{4}{ }^{+}$ during snow metamorphism might significantly change acid-base equilibria and buffer capacities within the snow microstructure, with direct consequences for air-ice chemical exchanges and chemical reactivity (Bartels-Rausch et al., 2014).

In this work, we monitor the redistribution of $\mathrm{NH}_{4}{ }^{+}$ with respect to five other major ions $\left(\mathrm{Ca}^{2+}, \mathrm{Cl}^{-}, \mathrm{F}^{-}, \mathrm{Na}^{+}\right.$, and $\mathrm{SO}_{4}{ }^{2-}$ ) during temperature gradient snow metamorphism 
with a series of elution experiments. Elution was chosen as method because it reveals the accessibility of different ions in complex multiphase settings and thus gives an indication of their distribution in snow. Due to the complexity of the underlying mechanisms, this study focuses on the overall change in accessibility of $\mathrm{NH}_{4}^{+}$rather than disentangling the underlying processes in detail. To address the diversity of snow in the environment, we investigate changes to the accessibility of ions in natural and artificial snow. Great care was taken to work with snow samples with concentration levels of solutes less than $1000 \mu \mathrm{g} / \mathrm{l}$ to ensure direct relevance and comparability of the results to the Alpine snowpack. The concentrations are comparable to the study of Hewitt et al. (1991) but significantly reduced compared to most laboratory studies (Grannas et al., 2007; Hullar and Anastasio, 2016) and correspond to the range measured in Alpine snow (Wagenbach et al., 1988; Baltensperger et al., 1993; Schwikowski et al., 1999). One key aspect of the study was to expose the snow samples to well defined temperature settings. For comparison, snow samples were stored at isothermal and temperature gradient conditions to clarify the impact of the vastly different metamorphism conditions. Metamorphism was performed for artificial and natural snow samples in a well-controlled laboratory setting for up to 3 months. The structure of the samples was monitored using computer tomography. Additionally, we investigated structural differences and ion distribution in samples taken from different depths of a natural snowpack that had undergone natural snow metamorphism to discuss the relevance of our findings for environmental settings. This approach allowed, for the first time, investigation of the microscale redistribution of $\mathrm{NH}_{4}{ }^{+}$with respect to other major ions during snow metamorphism.

\section{MATERIALS AND METHODS}

This study combines the preparation of doped artificial snow or sampling of natural snow, metamorphism experiments, and recording elution series of the ions $\mathrm{Ca}^{2+}, \mathrm{Cl}^{-}, \mathrm{F}^{-}, \mathrm{Na}^{+}$, $\mathrm{NH}_{4}{ }^{+}$, and $\mathrm{SO}_{4}{ }^{2-}$. All tools and containers used during snow production, sampling, and elution were carefully pre-cleaned 5 times with ultrapure water $\left(18 \mathrm{M} \Omega \mathrm{cm}\right.$ quality, arium ${ }^{\circledR}$ pro, Sartorius, Göttingen, Germany).

\section{Preparation of Artificial and Natural Snow Samples \\ Preparation of Artificial Snow}

Artificial snow was produced by shock freezing sprayed droplets of a sample solution in liquid nitrogen. This method of snow production has already been successfully applied in other studies (Bartels-Rausch et al., 2004, 2013; Matykiewiczová et al., 2007; Kerbrat et al., 2010). The sample solutions with defined concentrations of the major ions $\mathrm{Ca}^{2+}, \mathrm{Cl}^{-}, \mathrm{F}^{-}, \mathrm{Na}^{+}, \mathrm{NH}_{4}{ }^{+}$, and $\mathrm{SO}_{4}{ }^{2-}$ were prepared by dissolving specific amounts of salts (p.a. quality, $\mathrm{CaCl}_{2}, \mathrm{NaF}$, and $\left.\left(\mathrm{NH}_{4}\right)_{2} \mathrm{SO}_{4}\right)$ in ultrapure water (18 M $\Omega \mathrm{cm}$ quality, arium ${ }^{\circledR}$ pro, Sartorius, Göttingen, Germany). In the cold room of the Paul Scherrer Institute at $-20^{\circ} \mathrm{C}$ the ice droplets were sieved to a size fraction of 300-600 $\mu \mathrm{m}$ in diameter. About $60 \mathrm{~g}$ of the snow samples were filled in pre-cleaned $160 \mathrm{ml}$ polypropylene (PP) containers (Faust, Schaffhausen, Switzerland). The bottom of each container was already pre-filled with $4 \times 10 \mathrm{ml}$ layers of frozen ultrapure water, to prevent the formation of an air gap at the bottom of the snow sample caused by the vapor flux during the aging. The containers were stored isothermally at $-20^{\circ} \mathrm{C}$ until the beginning of the metamorphism experiment. The bulk concentrations, $\mathrm{c}_{\mathrm{Bulk}}$, of the different major ions in the sieved snow samples were determined in triplicate analyses using ion chromatography (IC). Concentrations varied between $\sim 380$ and $1000 \mu \mathrm{g} / \mathrm{l}$ (Table 1).

\section{Sampling of Natural Snow at WFJ}

After a major snowfall event on April 4th, 2017, $20 \mathrm{~kg}$ of fresh snow were collected from the Weissfluhjoch site (WFJ) in the Swiss Alps above Davos (2536 m a.s.ls, $46^{\circ} 49^{\prime} 47^{\prime \prime} \mathrm{N}$ $9^{\circ} 48^{\prime} 33^{\prime \prime} \mathrm{E}$ ). The site is a reference CryoNet station (Marty and Meister, 2012). The snow was sampled into a plastic box using a pre-cleaned Teflon shovel. The plastic box was sealed and placed in an insulated container during the transport. In a $-20^{\circ} \mathrm{C}$ laboratory at the WSL-Institute for Snow and Avalanche Research SLF, the snow was stirred using a Teflon rod to obtain a homogeneous snow sample. Bulk concentrations, $\mathrm{c}_{\mathrm{Bulk}}$, of the major ions in the WFJ snow samples were determined in triplicate analyses by IC and are presented in Table 1. The natural snow samples were subsampled in $160 \mathrm{ml}$ PP containers (as described in the section "Preparation of Artificial Snow") and isothermally stored at $-20^{\circ} \mathrm{C}$ until the beginning of the metamorphism experiment.

TABLE 1 | Comparison of the bulk concentrations $C_{\text {Bulk }}$ for the different ions in $\mu \mathrm{g} / \mathrm{l}$ together with the standard deviation based on the analyses of 3 samples.

\begin{tabular}{|c|c|c|c|c|c|c|c|c|}
\hline & Age & Ammonium & Calcium & Chloride & Fluoride & Sodium & Nitrate & Sulfate \\
\hline & days & $\mu \mathrm{g} / \mathrm{l}(\mu \mathrm{eq} / \mathrm{l})$ & $\mu g / l(\mu e q / l)$ & $\mu \mathrm{g} / \mathrm{l}(\mu \mathrm{eq} / \mathrm{l})$ & $\mu g / l(\mu e q / l)$ & $\mu \mathrm{g} / \mathrm{l}(\mu \mathrm{eq} / \mathrm{l})$ & $\mu g / l(\mu e q / I)$ & $\mu g / l(\mu e q / l)$ \\
\hline Artificial snow & - & $381 \pm 10(21)$ & $548 \pm 42(27)$ & $1003 \pm 25(28)$ & $851 \pm 55(45)$ & $1013 \pm 57$ (44) & - & $1024 \pm 30(21)$ \\
\hline Natural snow & - & $1029 \pm 5(57)$ & $99 \pm 7$ (4.9) & $52 \pm 4(1.5)$ & $8 \pm 0.2(0.4)$ & $18 \pm 2(0.8)$ & $1838 \pm 47(30)$ & $939 \pm 6(20)$ \\
\hline \multirow[t]{4}{*}{ Natural snowpack } & 0 & $1029 \pm 5(57)$ & $99 \pm 7$ (4.9) & $52 \pm 4(1.5)$ & $8 \pm 0.2(0.4)$ & $18 \pm 2(0.8)$ & $1838 \pm 47(30)$ & $939 \pm 6(20)$ \\
\hline & 30 & $138 \pm 8(7.7)$ & $27 \pm 4(1.4)$ & $25 \pm 4(0.7)$ & $<0.5(<0.03)$ & $10 \pm 1(0.5)$ & $218 \pm 12$ (3.5) & $83 \pm 9(1.7)$ \\
\hline & 60 & $11 \pm 1(0.6)$ & $22 \pm 1(1.1)$ & $44 \pm 1(1.2)$ & $<0.5(<0.03)$ & $18 \pm 1(0.8)$ & $257 \pm 8(4.1)$ & $36 \pm 1(0.8)$ \\
\hline & 90 & $14 \pm 1(0.8)$ & $157 \pm 5(7.8)$ & $19 \pm 2(0.5)$ & $0.58 \pm 0.02(0.03)$ & $17 \pm 0.4(0.7)$ & $196 \pm 10$ (3.2) & $104 \pm 4$ (2.2) \\
\hline
\end{tabular}

Concentrations in $\mu$ eq/l were additionally calculated following: $c(\mu e q / l)=z^{*} c(\mu g / l) / M(z$-ionic charge number, $M$-molar mass) and are given in brackets. 


\section{Controlled and Natural Metamorphism}

In total, we examined three different combinations of snow type and metamorphism:

(a) artificial snow exposed to a laboratory-controlled temperature gradient.

(b) natural snow exposed to a laboratory-controlled temperature gradient.

(c) natural snow from different depths of a snow pit at WFJ, that was exposed to natural metamorphism.

The combinations and the number of samples are listed in Table 2.

\section{Laboratory-Controlled Metamorphism Experiment}

The $160 \mathrm{ml}$ PP containers holding the snow samples were mounted onto a heating plate set to $-4^{\circ} \mathrm{C}$ at the base of a metamorphism box (Figure 1A). The metamorphism box (outside dimensions: $140 \mathrm{~cm} \times 70 \mathrm{~cm} \times 60 \mathrm{~cm}$, located at the SLF) offered space for up to 28 containers. The box was filled with a $4 \mathrm{~cm}$ ice layer, that is, to the same height as the ice layer in the sample containers. The remaining space around the sample holders was filled with sieved snow (about $6 \mathrm{~cm}$ depth to the cap of the sample holders). The metamorphism box was covered with a thin aluminum plate to inhibit sublimation of the filled-in snow. The laboratory temperature was held at $-8^{\circ} \mathrm{C}$. Effective temperatures at the top and bottom of the $6 \mathrm{~cm}$ thick snow samples were -6.5 and $-4.1^{\circ} \mathrm{C}$, respectively, corresponding to a temperature gradient of $40 \mathrm{~K} / \mathrm{m}$. The snow samples were stored in the metamorphism box for $0,3,6,12$, 30,60 , and 90 days, respectively. At the end of each storage period, the corresponding containers were removed and prepared for the elution experiments. In order to keep the conditions steady throughout the experiment, empty spaces from removed containers were filled up with snow-filled dummy containers.

In addition to the snow samples aged at the defined temperature gradient in the metamorphism box, we stored samples of artificial and natural snow at isothermal conditions $\left(-20^{\circ} \mathrm{C}\right)$ for a 90 -day period. Samples were stored inside a multilayer box out of steel plates $(1 \mathrm{~cm}$ thick) and styrofoam (2 and $5 \mathrm{~cm}$ thick) according to Löwe et al. (2011) to maintain a homogeneous temperature of $-20^{\circ} \mathrm{C}$. In Table 2, an overview of all used containers is given. For the artificial snow samples, we used two containers for the 0-, 6-, 12-, and 30-day batches, respectively: One for the elution experiment and one for monitoring structural changes using $\mathrm{X}$-ray microcomputed tomography (microCT). For the 3-day batch, we had only one container (elution), for the 60 -day batch 4 containers (triplicate elution/microCT) and for the 90-day isothermal sample only 1 container (microCT) as well. For the natural snow, we used 4 containers for each 0-, 3-, 6-, 12-, 30-, 60-, and 90-day batch (triplicate elution/microCT), and two containers (elution/microCT) for the 90-day isothermal batch. As initial state " 0 day" we define all states of metamorphism up to and including a duration of $24 \mathrm{~h}$.

\section{Natural Metamorphism: Samples of Natural Snow From a WFJ Snow Pit}

In addition to the collected surface snow (see section "Sampling of Natural Snow at WFJ"), we sampled $1 \mathrm{~kg}$ of snow at 3 different depths of a snow pit at the field site, WFJ. Each sample corresponded to a snowfall in January, February, March, and April 2017 and an age of 90, 60, 30, and 0 days, respectively. This snow was filled into pre-cleaned plastic boxes and transported frozen to the SLF cold lab. In the laboratory at $-20^{\circ} \mathrm{C}$, the snow was stirred with a Teflon rod and four $60 \mathrm{~g}$ subsamples of each sample were filled into $160 \mathrm{ml} \mathrm{PP}$ containers (Table 2, triplicate elution plus microCT sample). Bulk concentrations, $\mathrm{c}_{\mathrm{Bulk}}$, of the different major ions in the snow pit samples are presented in Table 1. The containers were isothermally stored at $-20^{\circ} \mathrm{C}$ until the beginning of the elution. These samples were not exposed to artificial temperature gradient metamorphism in the metamorphism box.

The age of the snow in the snow profile was determined based on the density evolution. Daily characterization of the snowpack at the WFJ field is conducted by the SLF every winter season; this includes density measurements with the Snow Micro Penetrometer SMP (Calonne et al., 2019). These measurements allowed us to monitor the stratigraphic evolution within the snowpack and to determine the age and depth of particular snow layers.

\section{Elution Experiments}

The elution experiments were performed in the cold room of the SLF at a temperature of $0^{\circ} \mathrm{C}$. All snow samples were tempered at $-0.2^{\circ} \mathrm{C}$ for $2 \mathrm{~h}$ prior to the elution experiments. Then the snow samples were extracted by removing the ice bottom using a ceramic knife and transferred into the elution column. The elution was performed in a $10 \mathrm{~cm}$ long plastic column with a diameter of $6 \mathrm{~cm}$ (Figure 1B). The samples were rinsed with an eluent of ultrapure water $\left(0^{\circ} \mathrm{C}\right)$. The eluent flow was set to $140 \mathrm{ml} / \mathrm{h}$ with the help of a drop regulator. After a specific saturation time of between $30 \mathrm{~min}$ and 1:45 $\mathrm{h}$ (Table 3) the

TABLE 2 | Combinations of metamorphism type and snow examined in this study.

\begin{tabular}{|c|c|c|c|c|c|c|c|c|c|}
\hline \multicolumn{2}{|c|}{ Metamorphism time (days) } & 0 & 3 & 6 & 12 & 30 & 60 & 90 & 90 isotherm \\
\hline Metamorphism & Samples & \multicolumn{8}{|c|}{ number of sample containers: Elution / microCT } \\
\hline Controlled (Lab) & Artificial snow & $1 / 1$ & $1 /-$ & $1 / 1$ & $1 / 1$ & $1 / 1$ & $3 / 1$ & $-1-$ & $-/ 1$ \\
\hline Controlled (Lab) & Natural snow & $3 / 1$ & $3 / 1$ & $3 / 1$ & $3 / 1$ & $3 / 1$ & $3 / 1$ & $3 / 1$ & $1 / 1$ \\
\hline Nature & Natural snowpack & $3 / 1$ & $-1-$ & $-1-$ & $-1-$ & $3 / 1$ & $3 / 1$ & $3 / 1$ & $-1-$ \\
\hline
\end{tabular}

The numbers of sample containers for the elution experiment and the microCT measurements are separated by a forward slash. 

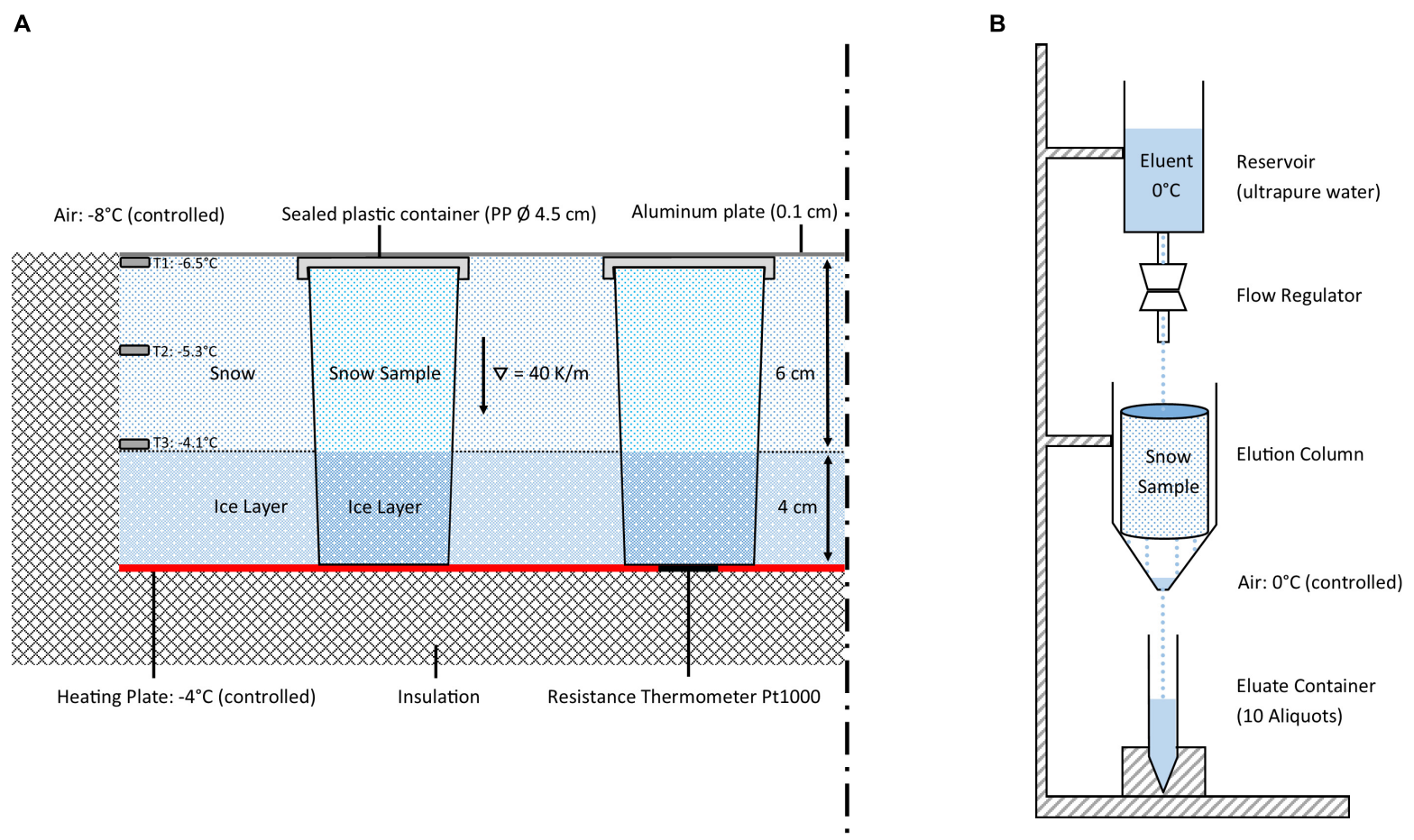

FIGURE 1 | (A) Scheme of the metamorphism box showing two sample containers (28 samples were stored). (B) Scheme of the elution setup. This setup was installed in the laboratory at $0^{\circ} \mathrm{C}$, a total of three elution stations could be run simultaneously.

eluate started to drip out at the outflow of the column and was collected in $15 \mathrm{ml}$ PP vials (Sarstedt, Nümbrecht, Germany). We collected 10 eluates for each elution experiment: the first 4 with a volume of $3 \mathrm{ml}$, the second 4 with $6 \mathrm{ml}$, and finally 2 with $12 \mathrm{ml}$ volume. During the elution experiment, the surface temperature of the elution station was monitored by an infrared thermometer to stay within $-0.5 \pm 0.5^{\circ} \mathrm{C}$. We assume that melting of the samples at this temperature and applying a $0^{\circ} \mathrm{C}$ eluent is negligible but cannot be excluded entirely. After the collection of the 10 eluates, the snow sample in the elution column, including the retained ultrapure water, was allowed to melt at room temperature. Two aliquots were collected in $50 \mathrm{ml}$
PP vials (Sarstedt, Nümbrecht, Germany). Procedural blanks taken during the elution experiments were always close to the detection limit for all investigated ions.

\section{Vertical Distribution of Ions After Temperature Gradient Storage}

To investigate the vertical distribution of the ion concentration within one sample, we split the microCT samples of the natural snow batch $(0,3,6,12,60,90$, and 90 days isothermal, Table 2) into two parts: One part was used to determine the microstructure in the microCT (see section "X-Ray Microtomography (microCT)"). The second part was used to

TABLE 3 | Saturation and Elution Time in [hh:mm]

\begin{tabular}{|c|c|c|c|c|c|c|}
\hline Age (days) & \multicolumn{2}{|c|}{ Artificial snow } & \multicolumn{2}{|c|}{ Natural snow } & \multicolumn{2}{|c|}{ Natural snowpack } \\
\hline 3 & 00:39 & $01: 57$ & $01: 44$ & 03:42 & - & - \\
\hline 6 & $01: 17$ & $03: 27$ & $01: 40$ & 03:20 & - & - \\
\hline 12 & 01:35 & 03:37 & $01: 21$ & 03:07 & - & - \\
\hline 90 & - & - & 01:06 & $02: 51$ & $00: 34$ & $02: 42$ \\
\hline 90 isotherm & - & - & 01:35 & 03:08 & - & - \\
\hline
\end{tabular}

The saturation time is the time from the start of the elution until the first drop of eluate drained out below the sample. Elution time represents the total time until the 10 th Eluate was collected, respectively $60 \mathrm{ml}$ of eluate had drained out and the sample was transferred to melting. 
analyze the vertical distribution of the ions. The $6 \mathrm{~cm}$ high snow samples were vertically cut into five $\sim 1.2 \mathrm{~cm}$ slices. The potentially contaminated surface of these slices was removed with a pre-cleaned ceramic knife and the decontaminated samples stored in $50 \mathrm{ml} \mathrm{PP}$ containers at $-20^{\circ} \mathrm{C}$ until IC analysis.

\section{Ion Chromatography (IC)}

Samples were kept at $-20^{\circ} \mathrm{C}$ until analysis at the Paul Scherrer Institute. Concentrations of the major cations $\mathrm{Ca}^{2+}, \mathrm{Na}^{+}$, $\mathrm{NH}_{4}{ }^{+}$, and anions $\mathrm{Cl}^{-}, \mathrm{F}^{-}, \mathrm{SO}_{4}{ }^{2-}$ in the different elution and snow samples were determined using ion chromatography (IC). A Metrohm (Herisau, Switzerland) 850 Professional IC combined with an 872 Extension Module and an 858 Professional Sample Processor autosampler was used for the analyses. Cations were separated using a Metrosep C4 column (Metrohm) and $2.8 \mathrm{mM}$ $\mathrm{HNO}_{3}$ as eluent at a flow rate of $1 \mathrm{ml} \mathrm{min}{ }^{-1}$. Anions were separated using a Metrosep A Supp 10 column (Metrohm) and were eluted stepwise using first, a $1.5 \mathrm{mM} \mathrm{Na}_{2} \mathrm{CO}_{3} / 0.3 \mathrm{mM}$ $\mathrm{NaHCO}_{3}$ (1:1 mixture) eluent, then an $8 \mathrm{mM} \mathrm{Na}_{2} \mathrm{CO}_{3} / 1.7 \mathrm{mM}$ $\mathrm{NaHCO}_{3}$ (1:1 mixture) eluent at a flow rate of $0.9 \mathrm{ml} \mathrm{min}{ }^{-1}$. Possible instrumental drifts were monitored by measuring an inhouse standard after every 20th sample. Detection limits were 10 , $1,0.5,0.5,0.5$, and $5 \mu \mathrm{g} / \mathrm{l}$ for $\mathrm{Ca}^{2+}, \mathrm{Cl}^{-}, \mathrm{F}^{-}, \mathrm{Na}^{+}, \mathrm{NH}_{4}{ }^{+}$, and $\mathrm{SO}_{4}{ }^{2-}$, respectively.

\section{X-Ray Microtomography (microCT)}

One sample of each batch (Table 2) was scanned for structural analysis using the microCT. The snow samples were extracted from the snow sample holder by separating the snow from the ice base layer. The snow samples were cut into a $1.5 \mathrm{~cm} \times 1.5 \mathrm{~cm} \times 6 \mathrm{~cm}$ column and mounted into a
microCT sample holder (diameter $2 \mathrm{~cm}$ ). The X-ray computed tomography scanner (Scanco microCT 40, SCANCO Medical AG, Switzerland) at the SLF was operated at a temperature of $-15^{\circ} \mathrm{C}$ and had a resolution of $10 \mu \mathrm{m}$. The reconstructed microCT images were filtered with a Gaussian filter (support 2 voxels, standard deviation 1 voxel) and the threshold for segmentation was applied according to Hagenmuller et al. (2014). Structural parameters of the segmented ice structure were extracted with the software tools of the microCT device (Image Processing Language, Scanco Medical).

\section{RESULTS}

\section{Structural Development}

Temperature Gradient Metamorphism

The microCT images in Figure $\mathbf{2}$ show the structural characteristics of the snow samples at different stages in metamorphism. These images display the drastic structural changes in the snow samples during metamorphism.

The initial structure of the two types of snow, natural and artificial, differed strongly. In artificial snow, the individual spheres of homogeneous diameter are partially recognizable while the natural snow shows the typical characteristics of fresh snow with branching (see Figures 2, 3, first column). In both types, the bonds between the individual particles are still little developed, so that the shape of the original deposited crystals can be presumed. Already after 12 days of storage time at a gradient of $40 \mathrm{~K} / \mathrm{m}$, the apparent differences between the two types of snow were much smaller. A significant coarsening of the structure was observed and a fully connected porous ice

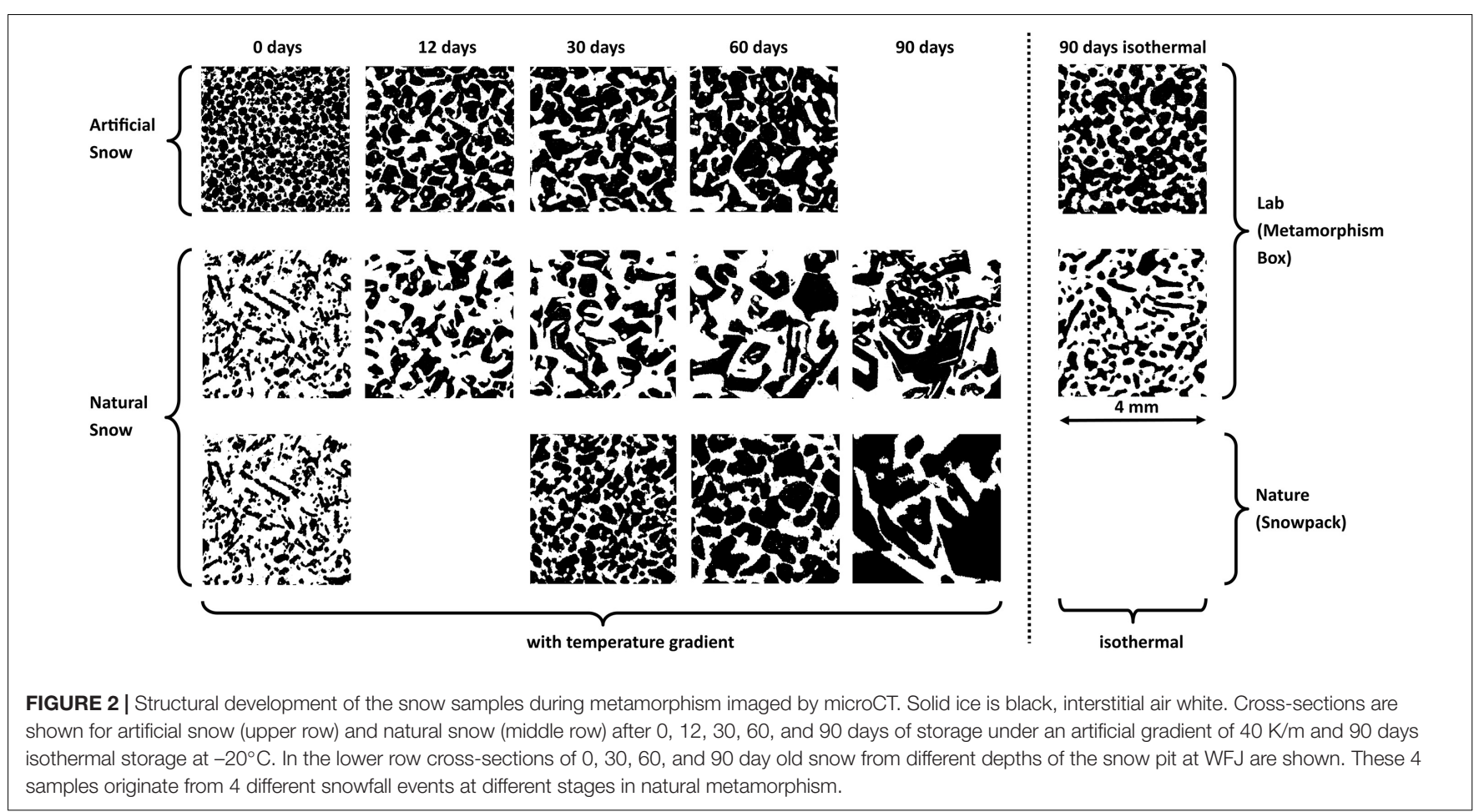




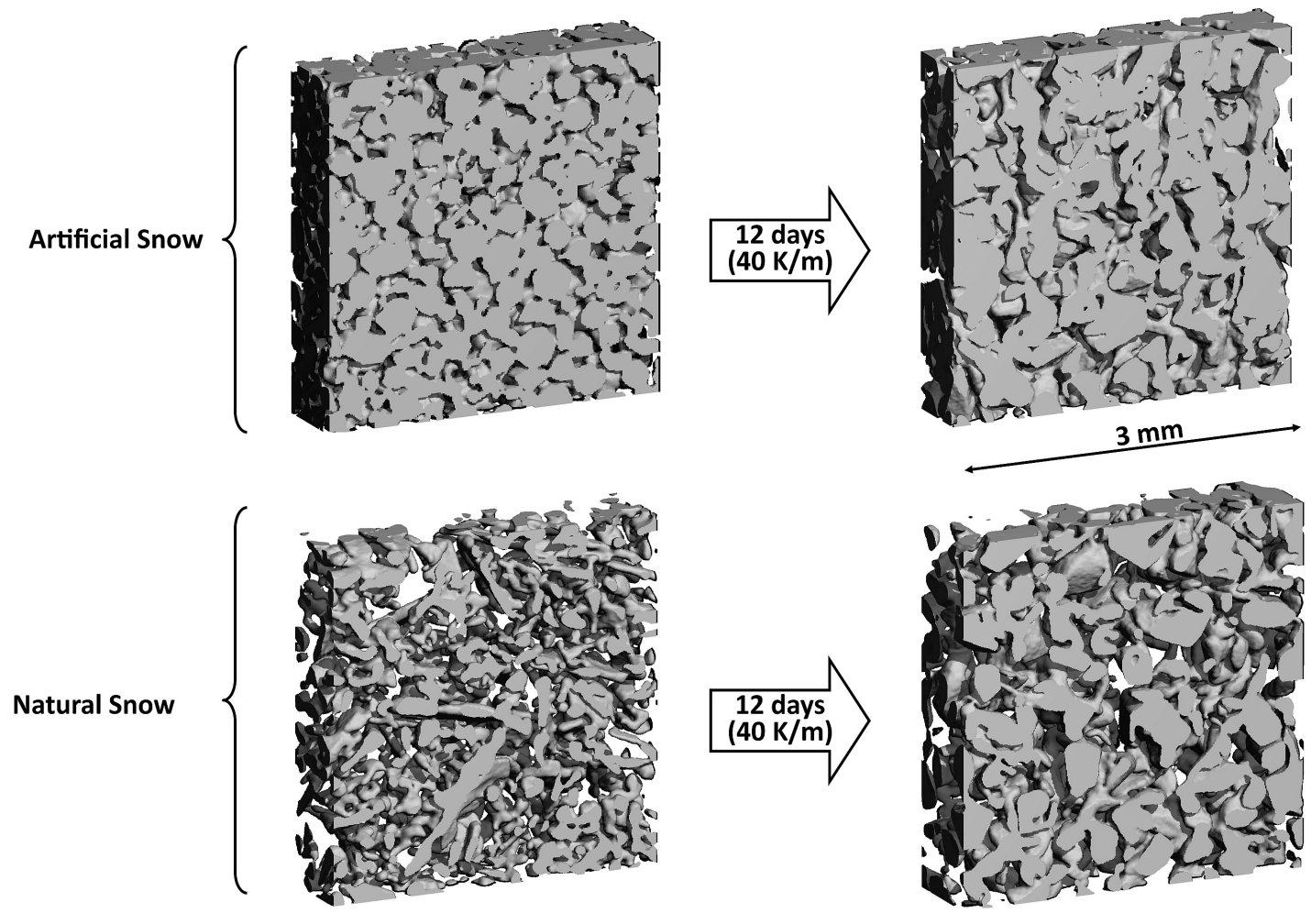

FIGURE 3 | Qualitative evolution (3D microstructure) of artificial and natural snow under an artificial temperature gradient of $40 \mathrm{~K} / \mathrm{m}$ imaged by microCT after 0 days (left) and 12 days (right). The dimensions of the observed sub-volume of the measured field of view are $3 \mathrm{~mm} \times 3 \mathrm{~mm} \times 0.5 \mathrm{~mm}$.

structure had grown in both the artificial and the natural snow. The reduction of the specific surface area (SSA) during this recrystallization is qualitatively visible: With increasing exposure time to the temperature gradient, the coarsening of the snow particles is further enhanced (Figure 2, 3rd to 5th column). The natural snowpack samples as third snow type showed a similar structural development. In fact, its 90-day sample had undergone the largest transformation compared to the initial state at day 0 (Figure 2, last row). The evolution of the SSA of the individual snow samples during the metamorphism experiment is shown in Figure 4. SSA of natural snow decreased by a factor of 2.2 from 27.0 to $12.2 \mathrm{~m}^{2} / \mathrm{kg}$ within 30 days. The initial decrease was less pronounced for artificial snow, showing a decrease from 15.9 to $12.2 \mathrm{~m}^{2} / \mathrm{kg}$ during the 1 st month. The development of the SSA in our experiments concur with results from experimental as well as modeling studies on dry metamorphism (Flanner and Zender, 2006; Taillandier et al., 2007; Pinzer et al., 2012). The snow samples taken from the WFJ depth profile showed similar SSA decrease during the first 30 days compared to the natural snow aged in the laboratory at $40 \mathrm{~K} / \mathrm{m}$ (Figure 4). Afterward, the SSA of the WFJ snow pit samples decreased below that of the natural and artificial samples exposed to a controlled temperature gradient.

The natural snow samples had a lower density $\left(\sim 400 \mathrm{~kg} / \mathrm{m}^{3}\right)$ than the artificial snow samples $\left(\sim 600 \mathrm{~kg} / \mathrm{m}^{3}\right)$. As the containers

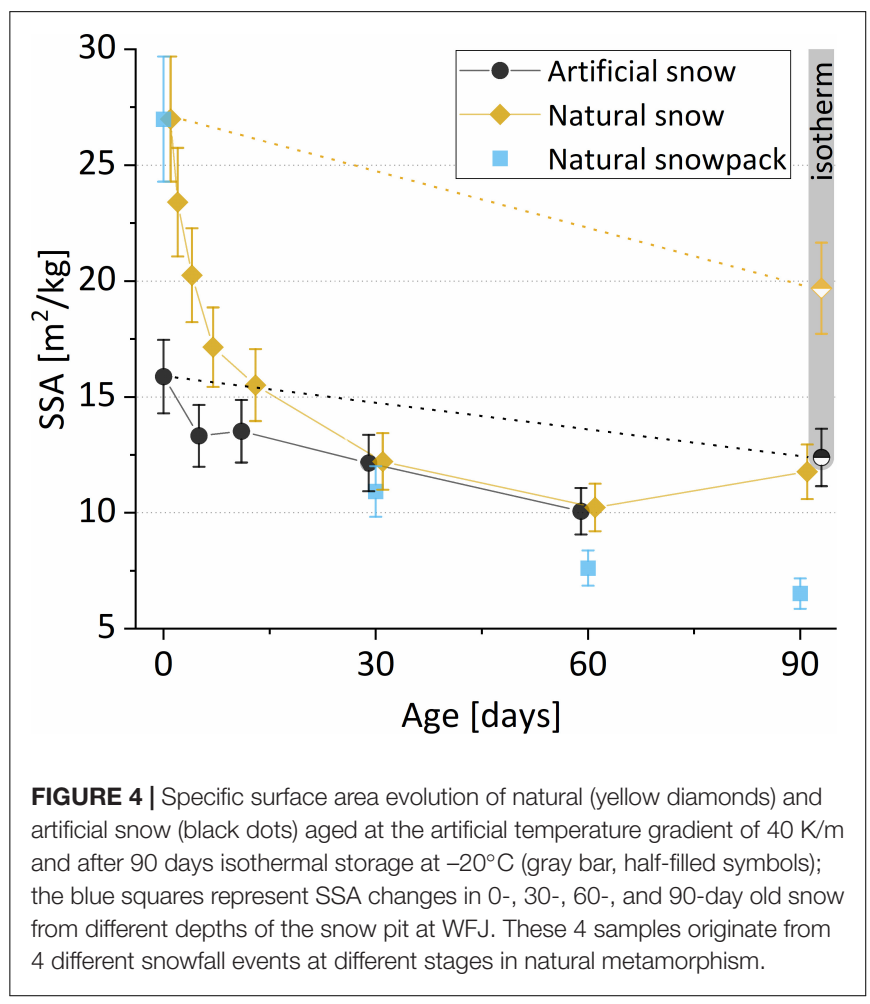


were sealed, bulk density remained almost constant during the course of the experiment.

\section{Isothermal Metamorphism}

The two samples isothermally stored at $-20^{\circ} \mathrm{C}$ for 90 days behaved differently than the ones exposed to the temperature gradient: Both artificial and natural snow samples experienced much less change without a temperature gradient, as shown in Figure 4. This is consistent with previous studies (Kaempfer et al., 2005; Taillandier et al., 2007). For artificial snow, the decrease in SSA from 15.9 to $12.4 \mathrm{~m}^{2} / \mathrm{kg}$ after 90 days was $\sim 22 \%$, corresponding to an aging time of $\sim 6-30$ days at a gradient of $40 \mathrm{~K} / \mathrm{m}$. The SSA of natural snow declined from 27 to $19.7 \mathrm{~m}^{2} / \mathrm{kg}$ after 90 days of isothermal storage; this decrease of $\sim 27 \%$ corresponds to an aging time of only $\sim 3-6$ days at a gradient of $40 \mathrm{~K} / \mathrm{m}$.

\section{Redistribution of $\mathrm{NH}_{4}{ }^{+}$and Other lons Elution Experiments}

Figure 5 presents the release profile of $\mathrm{Ca}^{2+}$ and $\mathrm{NH}_{4}^{+}$ during the elution of WFJ snow samples exposed to controlled metamorphism for 0 and 30 days. Concentrations of all six investigated major ions decreased between the 1st and 10th eluate, as exemplarily shown for $\mathrm{NH}_{4}{ }^{+}$and $\mathrm{Ca}^{2+}$ in Figure 5. The concentration in the first eluate, $c_{A}$, reflects the concentration of impurities that are best accessible by the eluent (Figures 5A,B, left gray bars). Their concentration in the eluate is given by the amount of eluted ions and the volume of eluent. In this work, concentrations were normalized to the bulk concentrations, $c_{\mathrm{Bulk}}$, of the original snow sample to allow for direct comparison between the different ions. Since $c_{B u l k}$ of $\mathrm{NH}_{4}{ }^{+}$is about 10 times larger than that of $\mathrm{Ca}^{2+}$ in the natural snow sample (see Table 1), Figure 5A reveals that the amount of $\mathrm{NH}_{4}{ }^{+}$in the first eluate exceeds that of $\mathrm{Ca}^{2+}$ by this same factor of 10 at the beginning of the metamorphism experiment (0 days). The concentration in the residual elution sample $c_{R}$ reflects the concentration of impurities that are least accessible by the eluent (Figures 5A,B, right gray bars). Generally, the ions with the highest concentration ratio $c_{A} / c_{B u l k}$ in the first eluate show the lowest concentration ratio $c_{R} / c_{B u l k}$ in the residual rest and vice versa (Figures 5A,B, right gray bars). A mass balance could be achieved within an uncertainty of $<40 \%$. The shape of the release profiles in Figure 5, where the majority of the ion load is found in the first few eluates is typical for contaminants that are readily eluted (Grannas et al., 2013). For example, laboratory elution experiments of water-soluble organics with melt water have shown that $3 / 4$ of each species is found in the first quarter of total eluates (Meyer et al., 2009a). This shape of the elution curve and in particular the absence of increasing concentration ratio toward the later part of the elution further indicates that release from insoluble aerosol deposits or other processes acting on longer time scales, such as chromatographic effects, can be neglected (Meyer et al., 2009a,b, 2011; Plassmann et al., 2010; Mann et al., 2011; Grannas et al., 2013). Support comes from a study by Hewitt et al. (1989) showing that ice surfaces do not lead to a chromatographic separation of $\mathrm{Cl}^{-}, \mathrm{NO}_{3}{ }^{-}$, and $\mathrm{SO}_{4}{ }^{2-}$ in elution experiments. In this work, we use the first eluate and the residual elution sample for further analysis.

The relative concentration in the residual elution sample $\mathrm{c}_{\mathrm{R}} / \mathrm{c}_{\text {Bulk }}$ are smaller than 1 for $\mathrm{NH}_{4}{ }^{+}$and $\mathrm{Ca}^{2+}$ in both sampling sets of 0 and 30 days (Figure 5, right gray bars). Obviously, $c_{R}$ of each, which is given by the amount of ions not accessible to the eluent and the dilution of the residual snow with eluent, is smaller than the respective bulk concentration. To assess the dilution, the mass of residual water and of the snow sample was noted for each experiment. Assuming that the water filling the void space in the residual sample still contains ions $(0.2$ concentration ratio is a typical value in the 10th eluate, Figure 5), a dilution to a concentration ratio of $\sim 0.7-0.8$ can be estimated. Clearly, the $c_{R} / c_{\text {Bulk }}$ ratio of 0.3 and 0.5 for $\mathrm{NH}_{4}{ }^{+}$and 0.4 and 0.3 for $\mathrm{Ca}^{2+}$ at 0 and 30 days (Figure 5), respectively, are significantly lower. Despite the uncertainties in potential melting and refreezing of ice by the eluent (see below), this back-ofthe-envelope estimate carefully suggests that the remaining snow after the elution is depleted in both ion concentration relative to their bulk concentrations. Since the accessible ion content was removed during the elution, these depleted ratios confirm qualitatively the ion's and ice's mass balance. As the dilution factors despite their large uncertainties are the same for all ions in a specific sample, we will focus on discussing their relative behavior in this work.

The relative increase of the $\mathrm{NH}_{4}{ }^{+} \mathrm{c}_{\mathrm{R}} / \mathrm{c}_{\mathrm{Bulk}}$ concentration ratio after 30 days compared to that of $\mathrm{Ca}^{2+}$ shows that $\mathrm{NH}_{4}{ }^{+}$is preferable found in the least accessible fraction after metamorphism. The comparison of the relative concentrations $\mathrm{c}_{\mathrm{A}} / \mathrm{c}_{\mathrm{Bulk}}$ in the first eluate for the samples aged for 0 and 30 days (Figure 5A vs. Figure 5B, left gray bars), show a strong trend as well: $\mathrm{Ca}^{2+}$ became even better accessible after 30 days. On the contrary, the $\mathrm{NH}_{4}{ }^{+}$concentration ratio in the first eluate did not significantly change between day 0 and 30 .

\section{Temporal Changes of Ion Concentrations in First Eluate and Residual Snow}

Figure 6 shows the temporal trend of the normalized ion concentrations in the first eluate, $c_{A} / c_{\text {Bulk }}$ (Figures $6 \mathrm{~A}-\mathrm{C}$ ), and $c_{R} / c_{\text {Bulk }}$ in the molten residual sample (Figures $6 \mathrm{D}-\mathrm{F}$ ). The $1 \sigma$ uncertainty for samples, where a 3 -fold determination was performed, is also shown. The partially large uncertainties result from potential sampling inhomogeneities, alterations in snow metamorphism (between different sites in the metamorphism box or in the field), variations during the elution process and analytical errors.

Generally, the $\mathrm{NH}_{4}{ }^{+}$concentration ratio showed a pronounced increase in the residual sample with time by about a factor of $2-3$ (Figures 6D,F) and $\sim 8$ (Figure 6E), whereas $\mathrm{SO}_{4}{ }^{2-}$ and $\mathrm{Ca}^{2+}$ ratios showed an increase in the first eluate. Depending on the different snow types, we observed varying trends with time for $\mathrm{Cl}^{-}, \mathrm{F}^{-}$, and $\mathrm{Na}^{+}$, the reasons for which will be discussed later:

\section{Controlled metamorphism, artificial snow (Figures 6A,D)}

There was a continuous rise of the $\mathrm{NH}_{4}{ }^{+}, \mathrm{Cl}^{-}, \mathrm{F}^{-}$, and $\mathrm{Na}^{+}$ concentration ratios in the residual snow during the 2 months 

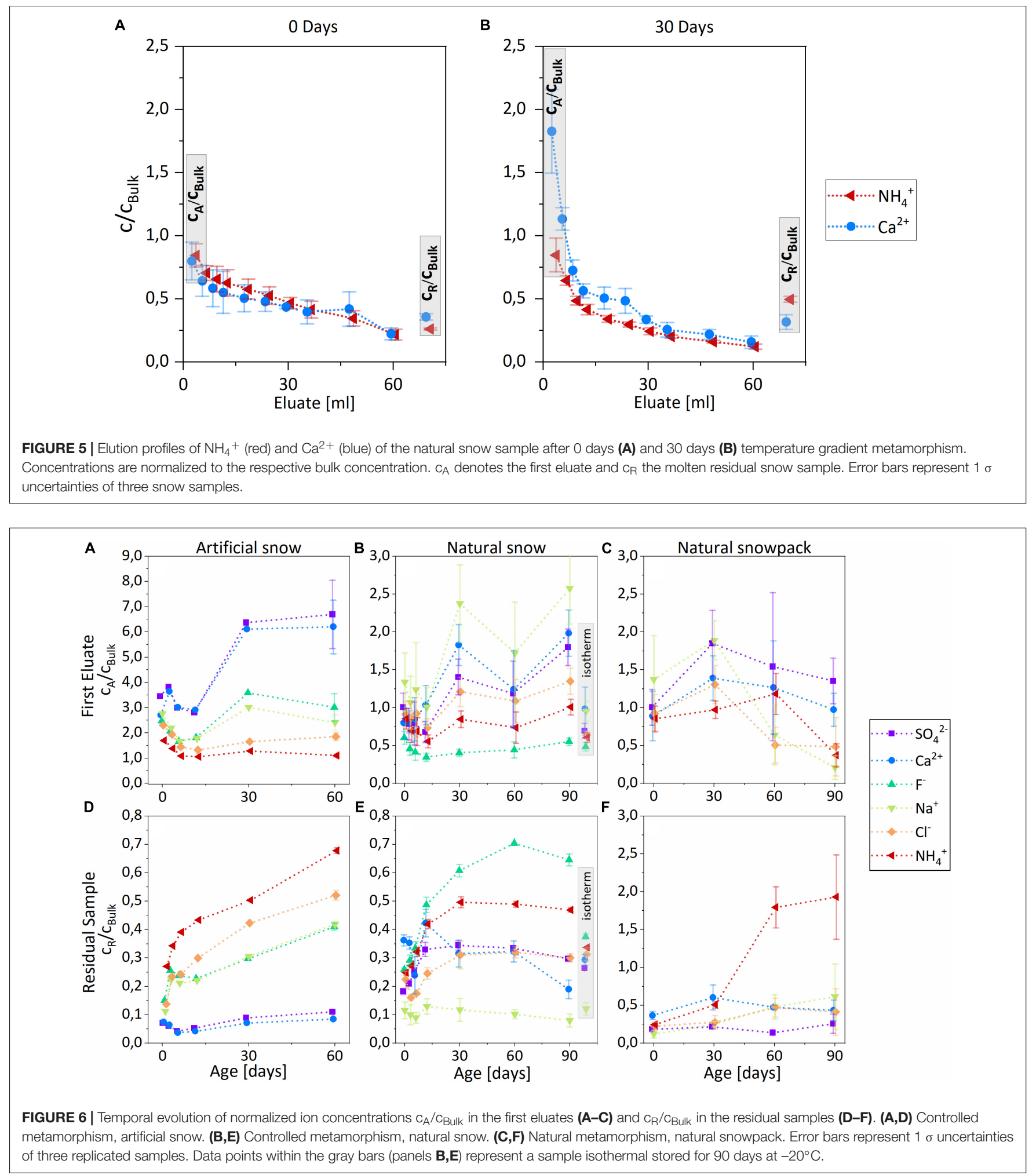

of aging; $\mathrm{NH}_{4}{ }^{+}$and $\mathrm{Cl}^{-}$showed the strongest increase. In the first eluate, concentrations ratios of all ions decreased during the first 12 days and afterward there was a strong enhancement in the $\mathrm{SO}_{4}{ }^{2-}$ and $\mathrm{Ca}^{2+}$ ratios.

\section{Controlled metamorphism, natural snow (Figures 6B,E)}

There was a continuous increase of the $\mathrm{F}^{-}, \mathrm{NH}_{4}{ }^{+}, \mathrm{Cl}^{-}$, and $\mathrm{SO}_{4}{ }^{2-}$ concentration ratios in the residual snow during the 1st month; $\mathrm{NH}_{4}{ }^{+}$and $\mathrm{F}^{-}$showed the strongest enrichment. 
Between 2 and 3 months, the concentration ratios of the four ions remained rather stable. The normalized concentrations of $\mathrm{Na}^{+}$and $\mathrm{Ca}^{2+}$ stayed almost constant with time. In the first eluate, we observed declining concentration ratios of all major ions during the first 12 days, followed by increasing values, most pronounced for $\mathrm{Na}^{+}$and $\mathrm{Ca}^{2+}$, during the 1st month. Concentration ratios of all ions remained relatively constant after the first 30 days.

\section{Natural metamorphism, natural snowpit (Figures 6C,F)}

$\mathrm{NH}_{4}{ }^{+}$concentrations in the residual sample increased with time, whereas the concentrations of $\mathrm{Cl}^{-}, \mathrm{SO}_{4}{ }^{2-}, \mathrm{Na}^{+}$, and $\mathrm{Ca}^{2+}$ did not significantly change. The concentration of $\mathrm{F}^{-}$was below the detection limit. In the first eluate, concentrations of all ions peaked after 30 days. After 90 days, $\mathrm{SO}_{4}{ }^{2-}$ and $\mathrm{Ca}^{2+}$ had the highest enrichment in the first eluate compared to other ions. Note: the 4 different snow samples $(0,30,60$, and 90 days) resulted from 4 different precipitation events and the metamorphism proceeded under unknown conditions.

\section{Temporal Changes in Ion Concentrations Under Isothermal Conditions}

Ion concentration ratios in the first eluate and the residual sample from the isothermally stored reference samples showed that there was little to no redistribution of the ions without temperature gradient compared to the samples of the same age exposed to temperature gradient (Figures 6B,E, gray inset). Chemical redistribution after 90 days of isothermal storage corresponds to the change after $\sim 6-12$ days at the temperature gradient.

\section{Enrichment of $\mathrm{NH}_{4}{ }^{+}$in the Residual Sample}

$\mathrm{NH}_{4}{ }^{+}$shows an overall very high ratio in the residual samples, indicating its low tendency to be expelled from the ice bulk (Figures 6D-F). After 30 days this ratio was significantly higher than that of any other ion except $\mathrm{F}$ - in the natural snow.

To qualitatively compare the enrichment of $\mathrm{NH}_{4}{ }^{+}$with that of the other ions in the residual sample and to correct for potential bias related to changes in the elution behavior and dilution caused by structural changes of the samples with time, we investigated the ratio of the ion concentration $c_{R} / c_{B u l k}$ (ion) to the $\mathrm{NH}_{4}{ }^{+}$concentration ratio $\mathrm{c}_{\mathrm{R}} / \mathrm{c}_{\mathrm{Bulk}}\left(\mathrm{NH}_{4}{ }^{+}\right)$, as shown in Figure 7. The comparison clearly shows that in artificial snow $\mathrm{NH}_{4}{ }^{+}$had the highest ratio in the residual sample compared to all other ions during the whole experiment, whereas $\mathrm{Ca}^{2+}$ and $\mathrm{SO}_{4}{ }^{2-}$ revealed always the lowest (Figure 7A). Furthermore, records of the $\mathrm{Na}^{+}, \mathrm{F}^{-}$and $\mathrm{Ca}^{2+}, \mathrm{SO}_{4}{ }^{2-}$ ratios agreed well for the whole 60 days period (Figure 7A). This is different for natural snow and the natural snowpack, where this "grouping" was not observed. Here, at the beginning of the experiment, the $\mathrm{Ca}^{2+}$ ratio was more enhanced in the residual snow compared to $\mathrm{NH}_{4}{ }^{+}$ (Figures 7 B,C). This changed after $\sim 12$ days in natural snow and $\sim 30$ days in the natural snowpack. In natural snow $\mathrm{F}^{-}$in the residual snow sample was higher in relation to $\mathrm{NH}_{4}{ }^{+}$right from the begin - this was even more pronounced with increasing storage time. We discuss this finding in the section "Accessibility of the Ions".

Changes of the ions' distribution in the samples stored isothermally for 90 days was insignificant compared to the same age with gradient (Figure 7B).

\section{Vertical Distribution of lons After Temperature Gradient Storage}

The comparison of the concentration ratio of the ions within the 5 parts $(\sim 1.2 \mathrm{~cm})$ of the vertically split snow samples did not show any significant differences. No vertical gradient was formed during the different stages of snow metamorphism.

\section{DISCUSSION}

Snow metamorphism alters the ice matrix in which impurities are embedded, and in particular, continues creating new ice surfaces. We debate the processes involved in snow metamorphism in the following two sections. This forms the basis for discussing

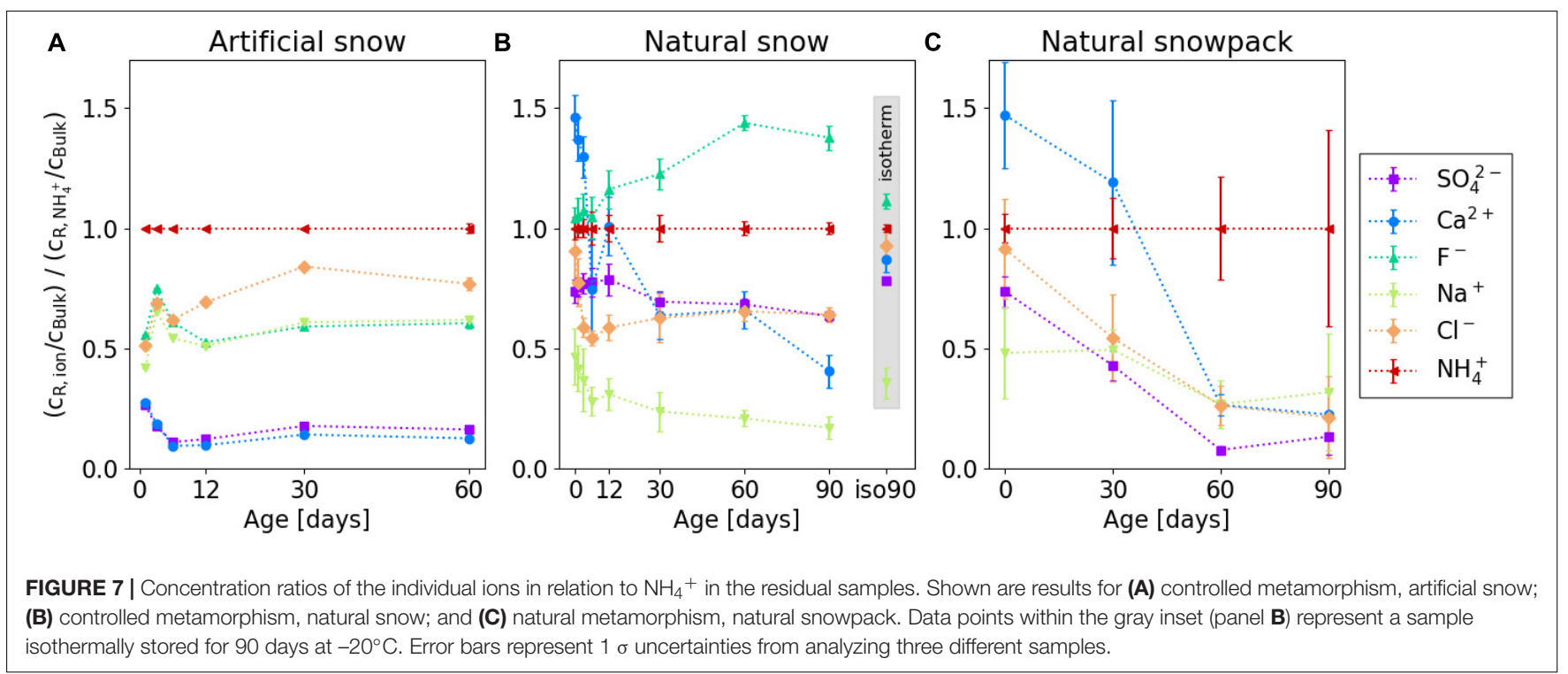


the driving processes for the relocation of chemical species, especially why the structural and chemical changes were more pronounced during temperature gradient metamorphism compared to isothermal metamorphism.

\section{Structural Changes \\ Temperature Gradient Metamorphism}

A temperature gradient in snow creates a water vapor pressure gradient. This gradient induces a diffusive flux from highpressure zones (warmer side of ice particles) to low pressure zones (colder side of ice particles) (Sokratov and Maeno, 1997; Pinzer et al., 2012). The net vapor flux is not a continuous flowthrough from the bottom to the top of a snowpack. Rather it takes place between adjacent crystals. Yosida et al. (1955) describes this process as "hand to hand transport." Further process details are described in Pinzer et al. (2012).

According to Pinzer et al. (2012) numerical simulations and experiments show that the vapor flux is almost structureindependent. Therefore, a constant temperature gradient leads to a constant water vapor flux. Some earlier studies based on simplified snow geometries concluded that the vapor diffusion coefficient is enhanced (Sommerfeld et al., 1987; Colbeck, 1993), while others (Voitkovskii et al., 1988; Sokratov and Maeno, 2000) concluded that there is no enhancement. A detailed discussion of this issue is given in Pinzer et al. (2012, p. 1042). Over time, the local rearrangements completely renew and thereby transform the structure of the original ice crystals. The lifetime of a particular ice volume is defined by the complete mass turnover and allows calculating its re-crystallization rate. Pinzer et al. (2012) showed a characteristic lifetime of 2-3 days for an ice volume at a gradient of $50 \mathrm{~K} / \mathrm{m}$. Accordingly, during our storage period of 90 days at a gradient of $40 \mathrm{~K} / \mathrm{m}$, the entire ice structure was continuously sublimated and rebuilt up to 40 times. This continuous rebuild is accompanied by a decrease in SSA (Taillandier et al., 2007), as observed in all experiments (Figure 4). However, even though the SSA decrease decelerated during the artificially induced metamorphism experiments (Figure 4), the re-crystallization rate did not change due to the constant temperature gradient.

Figure 4 shows that the initial SSA decrease in the artificial snow was much less pronounced compared to natural snow. This difference is due to the absence of fine crystal structures that would induce rapid SSA reduction during metamorphism. The absence of small structures in artificial snow resulted, on the one hand, from the round shape of the snow particles due to the production method and, on the other hand, from the subsequent sieving (see section "Preparation of Artificial Snow"). After 12 days, the artificial and the natural snow showed a comparable pattern: An anisotropic structure was formed from the isotropic starting material as shown in Figure 3. Moreover, the SSA values converged to a very similar value within an uncertainty of $\sim 10 \%$; in agreement to earlier work concluding that the SSA of artificial snow agrees well with that of metamorphosed natural snow (Bartels-Rausch et al., 2004).

The samples taken directly from the different depths of the WFJ snow pit had been exposed to varying temperature gradients in the field. Within the temperature profile of a natural snowpack often a diurnal cycle is visible: The lower temperatures at night cool the snow surface, leading to stronger gradients at night than during the day, while warming by the sun during the day leads to an increase in the snow surface temperature which may reverse the gradient in the snowpack. The SSA after 60 and 90 days of natural metamorphism was lower compared to that of the laboratory study. This is caused by the lower density and the higher average temperature of the WFJ site (Kaempfer et al., 2005).

\section{Isothermal Conditions}

The development of the SSA under isothermal condition showed only a small change (Figure 4, dotted lines). This can be explained by a much lower re-crystallization rate. In absence of a temperature gradient, the re-crystallization is driven by the differences in surface energy (Löwe et al., 2011). There is a natural tendency to minimize those differences by reducing the local curvature of particular ice structures (Kerbrat et al., 2008). Dendritic snow crystals are thereby progressively rounded (Flin et al., 2004). The flux due to the curvature reduction is significantly smaller than the one due to the temperature gradient and therefore, this process is much slower (Kaempfer et al., 2005).

Figure 2A (last column) clearly shows that the resulting structural changes are relatively small. The images confirm that the structure is still isotropic: After 90 days of isothermal storage, the original structure of the artificial snow was still visible. Only the bonding between the original particles increased. In natural snow, the single crystals were generally preserved and visible. However, these crystals were visibly rounded, as the edged contours had disappeared due to the reduction of the surface energy (Löwe et al., 2011).

In contrast to the temperature gradient metamorphism, changes in SSA during isothermal storage can be used as direct measure of the re-crystallization rate: A reduction in SSA of $22 \%$ for artificial snow represents roughly a mass turnover of around $80 \%$ during 90 days. The estimation is based on the conversion of the SSA into equivalent sphere diameters $(D=6 / S S A)$ and the resulting change in volume of the spheres. This compares to a turnover of up to $4000 \%$ during temperature gradient metamorphism, corresponding to the 40 re-crystallization cycles during the same time interval. This strong transformation, in which the entire ice structure is altered, forms the basis of our hypothesis that temperature gradient metamorphism has a strong effect on the (re-)distribution of the chemical species contained in snow, whereas less chemical changes are expected under isothermal conditions.

\section{Rearrangement of $\mathrm{NH}_{4}{ }^{+}$and Other Major Ions During Snow Metamorphism}

Progressing snow metamorphism in the laboratory and the field led to an enhanced incorporation of $\mathrm{NH}_{4}{ }^{+}$into less accessible ice interior regions. This occurred for all snow types. In the following we will relate structural changes of the snow during metamorphism to the observed locality of $\mathrm{NH}_{4}{ }^{+}$in the snow. 


\section{Initial Chemical Characterization of the Snow Artificial snow}

The artificial snow was produced by shock freezing a stock solution of $\mathrm{Ca}^{2+}, \mathrm{Cl}^{-}, \mathrm{F}^{-}, \mathrm{Na}^{+}, \mathrm{NH}_{4}^{+}$, and $\mathrm{SO}_{4}{ }^{2-}$ and stored at $-20^{\circ} \mathrm{C}$. The initial location of impurities in ice is a strong function of concentration, species, and freezing conditions (Bartels-Rausch et al., 2014). Generally, since the solubility of impurities is much lower in ice than in water, solutes are largely expelled from the forming ice when freezing from a solution. A second phase at air-ice interfaces, ice-ice interfaces of grain boundaries, or in internal micropockets forms (see section "Accessibility of the Ions"). Interestingly, the analysis of the artificial snow revealed prominent ion-pairs that persist during the entire metamorphism period. Here, $\mathrm{Ca}^{2+}$ and $\mathrm{SO}_{4}{ }^{2-}$, $\mathrm{Na}^{+}$and $\mathrm{F}^{-}, \mathrm{NH}_{4}{ }^{+}$, and $\mathrm{Cl}^{-}$are grouped (Figures 6A,D, 7A). It appears that we have the following salts precipitating during the shock-freezing of the artificial snow: $\mathrm{NaF}$ at $-3^{\circ} \mathrm{C}$, $\mathrm{CaSO}_{4}$ and $\mathrm{NH}_{4} \mathrm{Cl}$ at $-15^{\circ} \mathrm{C}$ as predicted by salt-water binary phase diagrams (Purdon and Slater, 1946; Melnikov, 1997; Lewis et al., 2010; Thomas and Dieckmann, 2010; Stefan-Kharicha et al., 2018). These ions-pairs may stay close also during the metamorphism experiments. The location of the second phase and other reservoirs in the snow will be discussed below.

\section{Natural snow}

The natural snow used for the 90-day metamorphism experiment in the laboratory contained mainly anthropogenically derived $\mathrm{NH}_{4} \mathrm{NO}_{3}$ and $\left(\mathrm{NH}_{4}\right)_{2} \mathrm{SO}_{4}$, explaining the majority of the ion balance (see Table 1). The origin of the other ions is less certain: $\mathrm{Ca}^{2+}$ (dust, $\mathrm{CaCO}_{3}, \mathrm{CaSO}_{4}$ ), $\mathrm{Na}^{+}$(sea salt $\mathrm{NaCl}, \mathrm{NaCO}_{3}$ ), $\mathrm{Cl}^{-}$ $\left(\mathrm{NaCl}, \mathrm{NH}_{4} \mathrm{Cl}\right)$, and $\mathrm{F}^{-}\left(\mathrm{NaF}, \mathrm{NH}_{4} \mathrm{~F}\right)$. In natural snow, the initial location of an ion in the snow structure is determined by scavenging processes in the atmosphere. Aerosol particles containing major ions can be incorporated in the snow crystal matrix, by acting as ice nuclei. On the other hand, direct impaction of aerosol particles on snow crystals or accumulation of supercooled water droplets onto ice crystal surfaces (riming) may lead to the enrichment of these species at the edges of the crystal (Mosimann et al., 2002; Pruppacher and Klett, 2004). $\mathrm{NH}_{4}{ }^{+}$is less likely to be within the ice nuclei (contrary to e.g., $\mathrm{Ca}^{2+}$ ), but rather scavenged by the latter two processes.

With progressing snow metamorphism, there is a strong relocation of the chemical compounds. Throughout our elution experiment, we monitored this change of ion location by studying their accessibility during elution with water.

\section{Accessibility of the lons}

Here, we differentiate between accessibility and preservation based on the elution behavior. The accessible fraction of the water-soluble ions are those that are eluted from the snow sample in the first $3 \mathrm{ml}$ eluate after a saturation time in the order of 1 to $2 \mathrm{~h}$ (Table 3). Preserved are those ions that are not washed out even after $2-3 \mathrm{~h}$ of complete elution.

Ions that are present at the ice surface are directly dissolved with the first eluent. Further, ions in grain boundaries are well known for their relatively fast diffusion and thus, effective transport of impurities from the interior of ice to the surface (Huthwelker et al., 2006). A back-of-the-envelope calculation based on the water self-diffusion in grain boundaries of $7 \times 10^{-13}$ $\mathrm{m}^{2} / \mathrm{s}$ ( Lu et al., 2009) suggests that within $1 \mathrm{~h}$ of saturation time during our elution experiments (Table 3), impurities could migrate $100 \mu \mathrm{m}$ through grain boundaries. To the best of our knowledge, the diffusion of ions from grain boundaries into interstitial water has not been investigated or compared to the release from the ice interface. Concerning gas - ice exchange processes, Bartels-Rausch et al. $(2004,2013)$ has shown that grain boundaries have no significant impact on the adsorption of volatile trace gasses. Extrapolation to the elution, i.e., the transfer from ice to water, is hampered by the very different time scales of the investigations and by the very distinct behavior of strong acids at the ice-air interface (Zimmermann et al., 2016; Kong et al., 2017). Given these uncertainties, we refrain from attributing the source of the accessible fraction of ions. Despite this uncertainty, the important point is that ions from either reservoir are accessible to percolating water in natural and artificial snow.

The fact that $\mathrm{Ca}^{2+}, \mathrm{SO}_{4}{ }^{2-}$, and $\mathrm{Na}^{+}$showed higher relative concentrations in the first eluate compared to other ions reflects the ease of their accessibility. A large fraction of these ions is either located at the air-ice interface or the ice-ice interface (within $100 \mu \mathrm{m}$ of the surface). This finding is in line with their low solubility in ice. In an analysis of ice core data, solubilities of $\mathrm{Na}^{+}, \mathrm{Ca}^{2+}$, and $\mathrm{SO}_{4}{ }^{2-}$ in the order of $2-10 \mu \mathrm{g} / \mathrm{l}$ have been suggested (Eichler et al., 2001). Thus, the low solubility of the latter 3 ions in ice and taken that we worked with concentrations of $500-1000 \mu \mathrm{g} / \mathrm{l}$ in artificial snow and $20-1000 \mu \mathrm{g} / \mathrm{l}$ in natural snow favors their presence at interfaces. In natural snow, an accumulation of $\mathrm{Ca}^{2+}$ in the residual part is visible on day 0 (Figures 6, 7). $\mathrm{Ca}^{2+}$ seems to have been exceptionally well protected from the eluent at the beginning of the experiment. This may be an indication that $\mathrm{Ca}^{2+}$ acted as ice nuclei (see section "Initial Chemical Characterization of the Snow"). This finding is in good agreement with observations that mineral dust particles preferably act as ice nuclei (Szyrmer and Zawadzki, 1997).

In general, $\mathrm{NH}_{4}{ }^{+}, \mathrm{F}^{-}$, and $\mathrm{Cl}^{-}$were found at very low concentration ratios in the first eluate, but with the highest concentration ratios in the residual sample. This general finding is consistent with their high solubility in ice. Phase diagrams of solid solutions are sparse, and we currently lack predictive capabilities of solute concentration in ice. Based on the atomic radii of $\mathrm{N}$ and $\mathrm{F}$ being comparable to that of an $\mathrm{O}$ atom, $\mathrm{NH}_{4}{ }^{+}$ and $\mathrm{F}^{-}$are generally thought to substituting water molecules, in the ice lattice (Hobbs, 1974; Pruppacher and Klett, 2010). Besides substitution, solutes may also fill interstitial space in crystals. Hobbs (1974) gives a solubility of about $2 \mathrm{~g} / \mathrm{l}$ for $\mathrm{NH}_{4}{ }^{+}$ and $\mathrm{F}^{-}$. As detailed by Hobbs and others (Huthwelker et al., 2006; Dominé et al., 2008) such solubility measurements are delicate and the apparent solubility can be significantly enhanced in presence of grain boundaries or if the thermodynamic equilibrium is not established, or if micropockets forms. We therefore caution when referring to this value. For $\mathrm{HCl}$ a solid solution solubility of $3 \mathrm{mg} / \mathrm{l}$ was derived by Thibert and Dominé (1997) in thermodynamically carefully controlled experiments 
on single crystalline ice. Whether this solubility reflects that of $\mathrm{Cl}^{-}$or of $\mathrm{HCl}$ is open to debate, as is the mechanism. However, concentrations of $\mathrm{NH}_{4}{ }^{+}, \mathrm{F}^{-}$, and $\mathrm{Cl}^{-}$in our snow samples are well below the solubility limits reported in the literature and suggests that they generally could be quantitatively incorporated into the ice structure.

Furthermore, micropockets can host impurities in ice. They are potentially present in shock-frozen ice (Hullar and Anastasio, 2016), such as our artificial snow, as well as in ice cores (Eichler et al., 2017, 2019). In principle, micropockets may be composed of salt deposits or liquid brine. In ice cores, for example, sulfate deposits appear to be common (Eichler et al., 2017, 2019). This might explain why we find sulfate at similar concentration ratio in the residual samples of natural snow as chloride, for which a very high solubility in ice crystals was found. Detailed laboratory studies have revealed that the number of micropockets in ice frozen from the liquid critically depends on the freezing rate and conditions as well as on the concentration of salt (Hullar and Anastasio, 2016; McFall et al., 2018). In shock-frozen ice, evidence was found for the presence of solutes in micropockets with a radius below $1 \mu \mathrm{m}$. In our shock frozen samples, we used significantly lower concentrations of ions by about a factor of 1000, also to minimize the occurrence of micropockets. However, with a total ion load of $410^{-6} \mathrm{~mol}$, one can estimate a total liquid volume of $5 \mu \mathrm{l}$ in the artificial snow. This would correspond to thousands of $1 \mu \mathrm{m}$ (radius) micropockets in each shock-frozen ice sphere of the artificial snow. For this back-of-the-envelope estimate, a typical concentration of brine that is in equilibrium with ice at $-5^{\circ} \mathrm{C}$ of $1.4 \mathrm{M}$ was used.

In summary, we have discussed solid solution, interfaces, micropockets and condensation nuclei as potential location of impurities in our snow samples. Despite the inability to clearly identify the location in our samples, we argued that impurities at the air-ice interface and to some extent at the ice-ice interface would represent easily accessible compartments. Whether the impurities form patches, micropockets or are present as induvial molecules there, is beyond the scope of this work. Solid solutions and internal grain micropockets represent reservoirs where the solutes are rather inaccessible.

\section{Impact of Structural Changes During Snow Metamorphism on the Redistribution of lons}

During the first $\sim 12$ days of the snow metamorphism, the concentration ratio of all accessible ions in the first eluate decreased. After $\sim 12$ days, $\mathrm{NH}_{4}{ }^{+}, \mathrm{Cl}^{-}$, and $\mathrm{F}^{-}$concentrations were gradually enhanced in the less accessible interior of the ice matrix, whereas $\mathrm{SO}_{4}{ }^{2-}$ and $\mathrm{Ca}^{2+}$ accumulated at the ice surface. Here we investigate how those findings relate to structural changes.

The general decrease in the concentration ratios of all ions during the first 12 days was concurrent with a reduction in the SSA (Figure 4). However, the SSA decline during the first 12 days was much more pronounced in the natural snow (drop from 27.0 to $15.5 \mathrm{~m}^{2} / \mathrm{kg}$ ) than in the artificial snow (drop from 15.9 to $13.5 \mathrm{~m}^{2} / \mathrm{kg}$; see section "Temperature Gradient Metamorphism"). Changes in the accessible fraction $c_{A} / c_{B u l k}$ of the ions in artificial and natural snow were rather similar in the meantime (decrease by a factor of $\sim 1.2-2$ between day 0 and 12 , see Figures 6A,B). Therefore, we conclude that changes in the SSA did not directly influence the accessibility of ions during the elution. This is not surprising. The surface area does indeed play a crucial role for exchange processes such as adsorption from the gas phase (Bartels et al., 2002; Kerbrat et al., 2008). In this study, however, the amount of accessible ions is not the result of a dynamic partitioning equilibrium. Rather, the absence of the SSA impact again confirms that the elution is not limited by the interface-water flux during elution.

In the first few days at best, the grain boundaries could play a role. Riche et al. (2012) demonstrated a loss of internal grain boundaries in artificial snow of up to $40 \%$ at isothermal storage at a temperature of $-5^{\circ} \mathrm{C}$. In our experiments, we expect even faster changes due to the high water vapor turnaround in temperature gradient metamorphism. With a gradient, grain boundaries move with the growing ice, eventually forming ice-ice interfaces when two growing areas meet (see Figure 8). How impurities respond to this is essentially unknown. However, the loss of internal grain boundaries during the initial stage of metamorphism would lead to a less effective transport of impurities from the interior of the ice to accessible surfaces and thus explain the decreasing concentrations of the ions.

Another hypothesis, that the initial decrease of $c_{A}$ could be the result of changes in the accessibility due to changes in residence time of the eluent, was not confirmed. In artificial snow, the shortest saturation time is observed for day 0 and 3 (Table 3). This can be explained by the poorly connected structure at the beginning of the experiment (see section "Structural Development") that led to a higher permeability. Thus, we expected a lower uptake of ions from the ice surface, as well as less exchange with potential pores and consequently a lower $c_{A}$. For day 6 and 12 the saturation time increased significantly without increasing $c_{A}$. Similarly, in the case of natural snow there was no correlation between residence time and $c_{A}$; during the first 12 days, the longest saturation time was contrasted with the smallest $c_{A}$. We conclude that the elution times have no influence on the results of the elution experiments. This is an important finding with regard to a further process that could influence the elution; wet snow metamorphism. As soon as there is liquid water present in the snowpack, new processes of transformation and particle growth occur (Brun, 1989). From the lack of correlation, we conclude that possible wet snow metamorphism processes play no significant role during the elution procedure. This finding is confirmed by the elution results of the isothermal samples (Figures 6B,E). Although these samples occasionally have the longest elution times (Table 3 ), there is barely any change in the ion distribution.

To conclude the most likely explanation for the observed decrease in the concentration ratios of all accessible ions in the first eluate during the initial $\sim 12$ days of the snow metamorphism is its relation to changes in the grain boundary content - and the re-location of impurities initially hosted there - driven by the continual complete re-structuring of the ice matrix during the temperature gradient metamorphism.

In the second phase of the performed elution experiment, between day 12 and 30, despite negligible changes in the $\mathrm{SSA}$, there was a significant enhancement of $\mathrm{SO}_{4}{ }^{2-}, \mathrm{Ca}^{2+}$ 


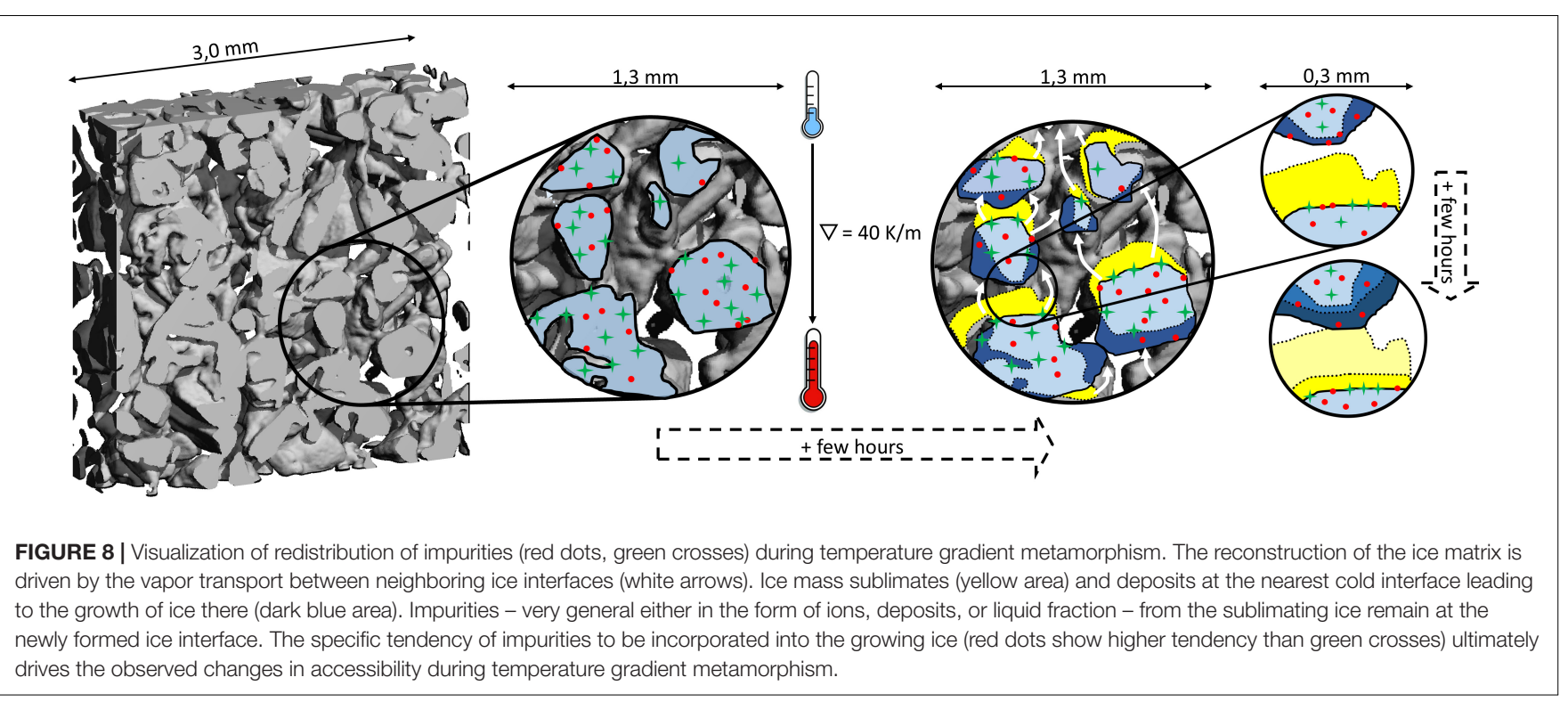

concentration ratios compared to the other ions at the accessible ice surface in artificial and natural snow samples. At the same time, $\mathrm{NH}_{4}{ }^{+}, \mathrm{Cl}^{-}$, and $\mathrm{F}^{-}$ratios increased in the ice interior.

Diffusion might act on these timescales to redistribute impurities particularly along grain-boundaries. Yet, diffusion is driven by concentration gradients (for example, between the interfaces and the interior). Due to the lack of knowledge about diffusion constants, we could only speculate why this should lead to a separation of $\mathrm{NH}_{4}{ }^{+}$and $\mathrm{Ca}^{2+}$. More importantly, diffusion as the main process can be excluded by comparing these results to those of the isothermal experiments, showing no such separation. The clear difference to the isothermal data strongly indicates that the observed distribution manifests themselves during the temperature gradient metamorphism.

Furthermore Hörhold et al. (2012) suggest that the densification of firn is enhanced by impurities. The preferred occurrence of $\mathrm{Ca}^{2+}$ at the accessible ice surface is in support of this hypothesis, as $\mathrm{Ca}^{2+}$ could enhance grain-boundary mobility during the densification process.

Volatile solutes can migrate with the water vapor from warm to cold areas of snow. Wagnon et al. (1999) have detected a displacement of $\mathrm{Cl}^{-}, \mathrm{F}^{-}$, and $\mathrm{NO}_{3}^{-}$in firn layers at high sulfuric acid concentrations. Indeed, the sorption to growing ice has also been found to be enhanced significantly for strong, volatile acids (De Angelis and Legrand, 1994; Dominé et al., 1995; Domine and Rauzy, 2004; Kärcher and Basko, 2004; Ullerstam and Abbatt, 2005; Kärcher et al., 2009). To test the relevance of this process, the concentration of ions was determined vertically along the sample. These vertical concentration profiles (see section "Vertical Distribution of Ions After Temperature Gradient Storage") give no indication of an enrichment along the vapor flux. This is in line with the initial presence of non-volatile compounds in our work (such as $\mathrm{NH}_{4} \mathrm{NO}_{3}$ and $\left(\mathrm{NH}_{4}\right)_{2} \mathrm{SO}_{4}$ in the natural snow (see section "Initial Chemical Characterization of the Snow"), and a low overall acidity, preventing the formation of volatile species. If therefore only pure water vapor sublimates during the metamorphism, the ions must remain at the interfaces of the remaining ice. Cragin et al. (1996) sketches a similar mechanism. However, this was based on the false assumption that large snow crystals continue to grow at the expense of small ones; although older and younger particles and ice surfaces exist in parallel, the maximum lifetime of an ice volume is limited to about 3 days (see section "Structural Change Under Temperature Gradient Metamorphism"). The noteworthy result is thus that the rearrangement continues over much longer timescales and is not related to changes in the SSA. Indeed, Pinzer et al. (2012) have shown that SSA is only a poor indicator of the dynamics in the snow during metamorphism and therefore not well suited to characterize the redistribution of embedded impurities. The change in SSA is only in the first phase of metamorphism related to vapor flux (and therefore, re-crystallization) because a quasisteady state is reached with respect to the SSA, but not for the re-crystallization during a constant temperature gradient driven water vapor flux.

At first view, the tendency of the ions to be hosted in the interior of ice - either as solid solution or in micropockets goes along with their solubility in ice. For species where the solubility is very likely exceeded such as $\mathrm{Ca}^{2+}$ and $\mathrm{SO}_{4}{ }^{2-}$, we find a larger part at the interfaces (Figure 8, green crosses). The explanation by solubility, however, does not go far enough to explain the observed relocation of ions at lower concentration than their solubility. If solubility would be the only argument, there should be no difference and no change with time between the ions $\mathrm{NH}_{4}{ }^{+}, \mathrm{F}^{-}, \mathrm{Cl}^{-}$, since solubility limit in ice was not reached for any of them. We therefore propose a more complex picture describing the fate of chemicals during temperature gradient metamorphism. It is based on the distribution equilibria between solid solution, partitioning to interfaces, and into micropockets. First it is important to note that ion redistribution in the isothermally stored samples was insignificant compared to the temperature gradient samples (Figure 7B), giving strong experimental evidence for the pivotal role of the re-crystallization 
TABLE 4 | Compilation of published elution sequences.

\begin{tabular}{|c|c|c|c|}
\hline$\#$ & Authors & Location & Sequence \\
\hline 1 & Brimblecombe et al., 1985 & Cairn Gorm Mt., Scotland & $\mathrm{SO}_{4}^{2-}>\mathrm{NH}_{4}^{+}>\mathrm{Ca}^{2+}>\mathrm{Na}^{+}>\mathrm{Cl}^{-}$ \\
\hline 2 & Eichler et al., 2001 & Upper Grenzgletscher, Swiss Alps & $\mathrm{SO}_{4}^{2-}>\mathrm{Ca}^{2+}>\mathrm{Na}^{+}>\mathrm{NH}_{4}^{+} \sim \mathrm{F}^{-}>\mathrm{Cl}^{-}$ \\
\hline 3 & Li et al., 2006 & Urumqi glacier No. 1, Tian Shan & $\mathrm{SO}_{4}^{2-}>\mathrm{Ca}^{2+}>\mathrm{Na}^{+}>\mathrm{Cl}^{-}>\mathrm{NH}_{4}^{+}$ \\
\hline 4 & Virkkunen et al., 2007 & Lomonosovfonna, Svalbard & $\mathrm{SO}_{4}^{2-} \sim \mathrm{Ca}^{2+}>\mathrm{Na}^{+} \sim \mathrm{Cl}^{-}>\mathrm{NH}_{4}^{+}$ \\
\hline 5 & Ginot et al., 2010 & Chimborazo, Ecuador & $\mathrm{SO}_{4}^{2-}>\mathrm{Ca}^{2+}>\mathrm{F}^{-}>\mathrm{Na}^{+}>\mathrm{Cl}^{-}>\mathrm{NH}_{4}^{+}$ \\
\hline 6 & You et al., 2015 & Urumqi Glacier No. 1, Tian Shan & $\mathrm{SO}_{4}^{2-}>\mathrm{Ca}^{2+} \sim \mathrm{Na}^{+}>\mathrm{Cl}^{-}>\mathrm{NH}_{4}^{+}$ \\
\hline 7 & Wang et al., 2018 & Baishui Glacier No. 1, Tibetan Plateau & $\mathrm{Ca}^{2+}>\mathrm{SO}_{4}^{2-}>\mathrm{NH}_{4}^{+}>\mathrm{Na}^{+}>\mathrm{Cl}^{-}$ \\
\hline 8 & Avak et al., 2019 & Weissfluhjoch, Swiss Alps & $\mathrm{SO}_{4}^{2-} \sim \mathrm{Ca}^{2+}>\mathrm{Na}^{+} \sim \mathrm{Cl}^{-}>\mathrm{NH}_{4}^{+}$ \\
\hline
\end{tabular}

of the ice matrix. Therefore, exchange between the solute's reservoirs is limited at isothermal conditions. Secondly, change in the distribution seems to continue for more than 60 days. This timescale is much longer than the lifetime of the ice matrix and the question arises why the preferential distribution of solutes is not reached earlier, when the ice matrix is completely reformed for the first time: Clearly, the evaporating ice leaves the impurities in whatever compartment behind irrespective of the specific compartment (see above), remaining at the newly formed interfaces (Figure 8). Ion-free ice grows at colder neighboring areas on interfaces that might hold ions with an ice growth rate of roughly $2 \mathrm{~nm} / \mathrm{s}$. For this estimation we assumed an optically equivalent diameter $D=0.4 \mathrm{~mm}(D=6 / \mathrm{SSA})$ and a lifetime of an imaginary ice particle of about $60 \mathrm{~h}$ (see section "Structural Change Under Temperature Gradient Metamorphism"). The ice growth rate has thus the same order of magnitude as the migration distance based on typical diffusivities in ice that are in the range of $7 \times 10^{16}$ to $2 \times 10^{14} \mathrm{~m}^{2} / \mathrm{s}$ for $\mathrm{HCl}$ and $\mathrm{HNO}_{3}$ (Thibert and Dominé, 1997, 1998). Thus $\mathrm{NH}_{4}{ }^{+}$and any impurity with both a diffusivity in that range and beneficial energetics of stabilization in the ice, can - driven by the strong concentration gradient - migrate into the newly formed ice forming a solid solution there. Taken the uncertainties in diffusivity, this estimate servers as rough upper limit. For ions that have a lower tendency to enter and be stabilized in the ice a smaller fraction enters the ice and a larger part remains at their initial location. With proceeding metamorphism, this location will end as air-ice interface, i.e., the location of these ions will more and more shift toward the accessible interfaces. Our data indicate that ions with a high solubility in ice also have a high tendency to be efficiently incorporated into growing ice (Figure 8, red dots), presumably because the same physical properties are at play in both processes.

For the qualitative comparison of the $\mathrm{NH}_{4}{ }^{+}$incorporation into the ice interior regions in relation to that of the other 5 ions during snow metamorphism, we formed enrichment sequences based on the ratio of the normalized ion concentration to the normalized $\mathrm{NH}_{4}{ }^{+}$concentration in the residual snow after 90 days (Figure 7). We obtained the following enrichment sequences for the 3 different experiments:

(a) laboratory-controlled metamorphism, artificial snow: $\mathrm{NH}_{4}{ }^{+}>\mathrm{Cl}^{-}>\mathrm{F}^{-} \sim \mathrm{Na}^{+}>\mathrm{SO}_{4}{ }^{2-} \sim \mathrm{Ca}^{2+}$

(b) laboratory-controlled metamorphism, WFJ snow: $\mathrm{F}^{-}>\mathrm{NH}_{4}^{+}>\mathrm{Cl}^{-} \sim \mathrm{SO}_{4}^{2-} \sim \mathrm{Ca}^{2+}>\mathrm{Na}^{+}$ (c) uncontrolled natural metamorphism, WFJ snow: $\mathrm{NH}_{4}^{+}>\mathrm{Cl}^{-} \sim \mathrm{Na}^{+}>\mathrm{SO}_{4}^{2-} \sim \mathrm{Ca}^{2+}\left(\mathrm{F}^{-}\right.$was below detection limit)

After 90 days of laboratory-controlled and natural snow metamorphism, $\mathrm{NH}_{4}{ }^{+}$was always one of the two ions most enriched in the less accessible ice interior.

The differences in the obtained enrichment sequences and thus the incorporation of the ions into the growing ice can be explained by different factors. The absolute concentration of ions plays a major role in the distribution of impurities in ice, as has been observed for trace elements in natural snow (Avak et al., 2019) and in earlier laboratory studies (Workman and Reynolds, 1950; Bartels-Rausch et al., 2014). For example, $\mathrm{F}^{-}$ concentrations in the artificial snow are two orders of magnitude higher than that of the WFJ snow samples (see Table 1). At higher concentrations, solubility might have been exceeded, explaining the less favorable $\mathrm{F}^{-}$incorporation in the less accessible ice interior in artificial compared to natural snow. Furthermore, chemical composition has a strong influence on the solubility of certain ions in ice. As an example, $\mathrm{NH}_{4}{ }^{+}$enhances the solubility of $\mathrm{F}^{-}$and $\mathrm{Cl}^{-}$in ice (Gross and Svec, 1997).

\section{Environmental Implications}

Our findings can directly be applied to interpret results of elution studies in the field. Climate warming induces melt processes significantly influencing the preservation of atmospheric pollutants in high-altitude snowpacks and glacier ice. Understanding the post-depositional behavior of different compounds is crucial for future reconstruction of past environmental conditions from these natural archives. A variety of studies has investigated the elution behavior of $\mathrm{NH}_{4}{ }^{+}$and other major ions from melting snowpacks and glacier ice. Table 4 presents a compilation of published elution sequences. This compilation contains only sites where $\mathrm{NH}_{4}{ }^{+}$was studied together with other major ions. Furthermore, for better clarity, the listed sequences contain only the 6 major ions investigated in our study, even though further ions may be available in some of the works.

The compilation shows that in all elution studies (except one) $\mathrm{NH}_{4}{ }^{+}$is together with $\mathrm{Cl}^{-}$the least mobile ion. Our study allows us, for the first time, to explicitly relate the preservation of $\mathrm{NH}_{4}{ }^{+}$at various sites affected by melting around the world to the burial of $\mathrm{NH}_{4}{ }^{+}$into the less accessible ice interior during snow metamorphism. Furthermore, the observed higher mobility 
of $\mathrm{SO}_{4}{ }^{2-}$ and $\mathrm{Ca}^{2+}$ compared to $\mathrm{NH}_{4}{ }^{+}$in the elution studies (Table 4) can be clearly related to a stronger gradual enrichment of these two ions at the accessible ice surface during snow metamorphism, favoring a meltwater relocation.

The obvious differences between the published elution sequences might be explained by the different metamorphism stages and temperature gradients of the investigated snowpack, as well as varying chemical composition, different sources and concentration levels, and acid input (Brimblecombe et al., 1987, 1988; Cragin et al., 1996; Gross and Svec, 1997; Wu et al., 2018). Another factor is the partial occurrence of wet snow metamorphism in some study areas compared to the assumed pure dry metamorphism investigated in our work (see section "Impact of Structural Changes During Snow Metamorphism on the Redistribution of Ions"). However, despite the dissimilarities between the different study sites, the general low mobility of $\mathrm{NH}_{4}{ }^{+}$due to the gradual burial in the less accessible ice interior indicates that $\mathrm{NH}_{4}{ }^{+}$is one of the best-suited environmental proxies even in snowpacks and ice cores affected by melting. The establishment of such meltwater-resistant proxies is particularly relevant as many high-mountain glaciers worldwide are retreating or are in danger of melting.

\section{CONCLUSION}

In this study, we investigated the redistribution of $\mathrm{NH}_{4}{ }^{+}$and five other major ions $\left(\mathrm{Ca}^{2+}, \mathrm{Na}^{+}, \mathrm{Cl}^{-}, \mathrm{F}^{-}\right.$, and $\left.\mathrm{SO}_{4}{ }^{2-}\right)$ during dry snow metamorphism of different snow types, i.e., shock-frozen artificial snow and natural snow.

Our results show that temperature gradient snow metamorphism in the laboratory and in the field leads to the incorporation of $\mathrm{NH}_{4}{ }^{+}$into less accessible ice interior regions. Exposed to a gradient of $40 \mathrm{~K} / \mathrm{m}$, the complete ice matrix of every sample was continuously rebuilt within 2 to 3 days, induced by the water vapor flux. We propose that the continuous reconstruction drives the selective incorporation of ions with a high solubility in ice $\left(\mathrm{NH}_{4}{ }^{+}, \mathrm{F}^{-}\right.$, and $\left.\mathrm{Cl}^{-}\right)$into interior regions and the rejection of others (including $\mathrm{Ca}^{2+}, \mathrm{SO}_{4}{ }^{2-}$ ) to the exterior (air-ice or ice-ice interface).

This distribution of the ions results from the specific balance of ice growth rate, diffusivity, chemical composition, and the tendency to enter the ice matrix. The absence of a relation to changes in the specific surface area confirms that this parameter is not a valid indicator of water vapor fluxes in temperature gradient metamorphism. During isothermal snow

\section{REFERENCES}

Abbatt, J. P. D. D., Thomas, J. L., Abrahamsson, K., Boxe, C., Granfors, A., Jones, A. E., et al. (2012). Halogen activation via interactions with environmental ice and snow in the polar lower troposphere and other regions. Atmos. Chem. Phys. 12, 6237-6271. doi: 10.5194/acp-12-62372012

Avak, S. E., Trachsel, J. C., Edebeli, J., Brütsch, S., Bartels-Rausch, T., Schneebeli, M., et al. (2019). Melt-induced fractionation of major ions and trace elements in an alpine snowpack. J. Geophys. Res. Earth Surf., 124. doi: 10.1029/ 2019JF005026 metamorphism, the chemical rearrangement was not significant. This can be explained by the low re-crystallization rate, which was two orders of magnitude lower than in the experiments with a temperature gradient of $40 \mathrm{~K} / \mathrm{m}$.

With progressing snow metamorphism, $\mathrm{NH}_{4}{ }^{+}$was always one of the two ions most enriched in the interior ice regions relative to the total amount. The comparability of our results for all studied snow types suggests that the redistribution of $\mathrm{NH}_{4}{ }^{+}$ in metamorphosing snow is independent on the snow type and thus, the findings can be widely applied to different snowpacks worldwide. This work explicitly links the observed preservation of $\mathrm{NH}_{4}{ }^{+}$at a number of melt-affected study sites to the incorporation into the ice interior during snow metamorphism. Accordingly, $\mathrm{NH}_{4}{ }^{+}$is one of the best-suited environmental proxies in snowpacks, firn and ice cores affected by melting.

\section{AUTHOR CONTRIBUTIONS}

AE, MS, and TB-R designed the study. AE supervised the experiments and data analysis. JT, SA, JE, MS, and AE designed, planned, and performed the experiments. JT, SA, and JE produced the artificial snow samples. JT, SA, JE, AE, and SB collected natural snow samples in the field. JT, SA, JE, and AE performed the elution experiments. JT prepared and analyzed the microCT samples, wrote the manuscript with input from all authors, and designed the figures. SB analyzed the chemical samples. JT and AE analyzed the data. AE, TB-R, and MS edited the manuscript. All authors approved the submitted version of the manuscript.

\section{FUNDING}

Funding for this study was provided by the Swiss National Science Foundation (SNSF) under Grant No. 155999.

\section{ACKNOWLEDGMENTS}

We are grateful to Matthias Jaggi (SLF) and Mario Birrer (PSI) for their technical assistance. We would like to thank Margret Matzl for her help in evaluating the microCT data and Bettina Richter for the help with Python. We greatly appreciate the comments and suggestions of the two reviewers FD and TK, which helped to improve the clarity of the manuscript.

Baltensperger, U., Schwikowski, M., Gäggeler, H. W., Jost, D. T., Beer, J., Siegenthaler, U., et al. (1993). Transfer of atmospheric constituents into an alpine snow field. Atmos. Environ. Part A Gen. Top. 27, 1881-1890. doi: 10.1016/ 0960-1686(93)90293-8

Barret, M., Domine, F., Houdier, S., Gallet, J. C., Weibring, P., Walega, J., et al. (2011a). Formaldehyde in the Alaskan Arctic snowpack: partitioning and physical processes involved in air-snow exchanges. J. Geophys. Res. Atmos. 116:D00R03. doi: 10.1029/2011JD016038

Barret, M., Houdier, S., and Domine, F. (2011b). Thermodynamics of the formaldehyde-water and formaldehyde-ice systems for atmospheric applications. J. Phys. Chem. A 115, 307-317. doi: 10.1021/jp108907u 
Bartels-Rausch, T., Eichler, B., Zimmermann, P., Gäggeler, H. W., and Ammann, M. (2002). The adsorption of nitrogen oxides on crystalline ice. Atmos. Chem. Phys. 2, 235-247. doi: 10.5194/acp-2-235-2002

Bartels-Rausch, T., Guimbaud, C., Gäggeler, H. W., and Ammann, M. (2004). The partitioning of acetone to different types of ice and snow between 198 and 223 K. Geophys. Res. Lett. 31:L16110. doi: 10.1029/2004GL020070

Bartels-Rausch, T., Huthwelker, T., Jöri, M., Gäggeler, H., and Ammann, M. (2008). Interaction of gaseous elemental mercury with snow surfaces: laboratoryinvestigation. Environ. Res. Lett. 3:45009. doi: 10.1088/1748-9326/3/ 4/045009

Bartels-Rausch, T., Jacobi, H. W., Kahan, T. F., Thomas, J. L., Thomson, E. S., Abbatt, J. P. D., et al. (2014). A review of air-ice chemical and physical interactions (AICI): liquids, quasi-liquids, and solids in snow. Atmos. Chem. Phys. 14, 1587-1633. doi: 10.5194/acp-14-1587-2014

Bartels-Rausch, T., Wren, S. N., Schreiber, S., Riche, F., Schneebeli, M., and Ammann, M. (2013). Diffusion of volatile organics through porous snow: impact of surface adsorption and grain boundaries. Atmos. Chem. Phys. 13, 6727-6739. doi: 10.5194/acp-13-6727-2013

Brimblecombe, P., Clegg, S. L., Davies, T. D., Shooter, D., and Tranter, M. (1987). Observations of the preferential loss of major ions from melting snow and laboratory ice. Water Res. 21, 1279-1286. doi: 10.1016/0043-1354(87)90181-3

Brimblecombe, P., Clegg, S. L., Davies, T. D., Shooter, D., and Tranter, M. (1988). The loss of halide and sulphate ions from melting ice. Water Res. 22, 693-700. doi: 10.1016/0043-1354(88)90180-7

Brimblecombe, P., Tranter, M., Abrahams, P. W., Blackwood, I., Davies, T. D., and Vincent, C. E. (1985). Relocation and preferential elution of acidic solute through the snowpack of a small, remote, high-altitude scottish catchment. Ann. Glaciol. 7, 141-147. doi: 10.3189/\$0260305500006066

Brun, E. (1989). Investigation on wet-snow metamorphism in respect of liquidwater content. Ann. Glaciol. 13, 22-26. doi: 10.3189/S0260305500007576

Calonne, N., Richter, B., Löwe, H., Jaggi, M., Fierz, C., Van Herwijnen, A., et al. (2019). "The RHOSSA campaign: monitoring the seasonal evolution of an alpine snowpack up to daily resolution," in Proceedings of the 20th EGU General Assembly conference on EGU2018, (Vienna).

Colbeck, S. C. (1993). The vapor diffusion coefficient for snow. Water Resour. Res. 29, 109-115. doi: 10.1029/92WR02301

Cragin, J. H., Hewitt, A. D., and Colbeck, S. C. (1996). Grain-scale mechanisms influencing the elution of ions from snow. Atmos. Environ. 30, 119-127. doi: 10.1016/1352-2310(95)00232-N

Dansgaard, W., Johnsen, S. J., and Clausen, H. B. (1973). Stable isotope glaciology. Meddelelser Om Gronl. 197, 1-54. doi: 10.1029/2018)D029619

De Angelis, M., and Legrand, M. (1994). Origins and variations of fluoride in Greenland precipitation. J. Geophys. Res. 99, 1157-1172. doi: 10.1029/ 93JD02660

Dominé, F., Albert, M., Huthwelker, T., Jacobi, H.-W. W., Kokhanovsky, A. A., Lehning, M., et al. (2008). Snow physics as relevant to snow photochemistry. Atmos. Chem. Phys. 8, 171-208. doi: 10.5194/acp-8-171-2008

Domine, F., and Rauzy, C. (2004). Influence of the ice growth rate on the incorporation of gaseous HCl. Atmos. Chem. Phys. 4, 2513-2519. doi: 10.5194/ acp-4-2513-2004

Dominé, F., and Shepson, P. B. (2002). Air-snow interactions and atmospheric chemistry. Science 297, 1506-1510. doi: 10.1126/science.1074610

Dominé, F., Thibert, E., Silvente, E., Legrand, M., and Jaffrezo, J.-L. (1995). Determining past atmospheric $\mathrm{HCl}$ mixing ratios from ice core analyses. J. Atmos. Chem. 21, 165-186. doi: 10.1007/BF00696579

Döscher, A., Gäggeler, H. W., Schotterer, U., and Schwikowski, M. (1996). A historical record of ammonium concentrations from a glacier in the Alps. Geophys. Res. Lett. 23, 2741-2744. doi: 10.1029/96GL0 2615

Eichler, A., Brütsch, S., Olivier, S., Papina, T., and Schwikowski, M. (2009). A 750 year ice core record of past biogenic emissions from Siberian boreal forests. Geophys. Res. Lett. 36:L18813. doi: 10.1029/2009GL038807

Eichler, A., Schwikowski, M., and Gäggeler, H. W. (2001). Meltwater-induced relocation of chemical species in Alpine firn. Tellus Ser. B Chem. Phys. Meteorol. 53, 192-203. doi: 10.3402/tellusb.v53i2.16575

Eichler, A., Tinner, W., Brütsch, S., Olivier, S., Papina, T., and Schwikowski, M. (2011). An ice-core based history of Siberian forest fires since AD 1250. Quat. Sci. Rev. 30, 1027-1034. doi: 10.1016/j.quascirev.2011.02.007
Eichler, J., Kleitz, I., Bayer-Giraldi, M., Jansen, D., Kipfstuhl, S., Shigeyama, W., et al. (2017). Location and distribution of micro-inclusions in the EDML and NEEM ice cores using optical microscopy and in situ Raman spectroscopy. Cryosphere 11, 1075-1090. doi: 10.5194/tc-11-1075-2017

Eichler, J., Weikusat, C., Wegner, A., Twarloh, B., Behrens, M., Fischer, H., et al. (2019). Impurity analysis and microstructure along the climatic transition from MIS 6 Into 5e in the EDML ice core using cryo-raman microscopy. Front. Earth Sci. 7:20. doi: 10.3389/feart.2019.00020

Flanner, M. G., and Zender, C. S. (2006). Linking snowpack microphysics and albedo evolution. J. Geophys. Res. 111:D12208. doi: 10.1029/2005JD006834

Flin, F., Brzoska, J. B., Lesaffre, B., Coléou, C., and Pieritz, R. A. (2004). Three-dimensional geometric measurements of snow microstructural evolution under isothermal conditions. Ann. Glaciol. 38, 39-44. doi: 10.3189/ 172756404781814942

Fuhrer, K., Neftel, A., Anklin, M., and Maggi, V. (1993). Continuous measurements of hydrogen peroxide, formaldehyde, calcium and ammonium concentrations along the new grip ice core from summit, Central Greenland. Atmos. Environ. Part A Gen. Top. 27, 1873-1880. doi: 10.1016/0960-1686(93) 90292-7

Fuhrer, K., Neftel, A., Anklin, M., Staffelbach, T., and Legrand, M. (1996). Highresolution ammonium ice core record covering a complete glacial-interglacial cycle. J. Geophys. Res. Atmos. 101, 4147-4164. doi: 10.1029/95JD02903

Ginot, P., Schotterer, U., Stichler, W., Godoi, M. A., Francou, B., and Schwikowski, M. (2010). Influence of the Tungurahua eruption on the ice core records of Chimborazo, Ecuador. Cryosphere 4, 561-568. doi: 10.5194/tc-4-561-2010

Grannas, A. M., Bogdal, C., Hageman, K. J., Halsall, C., Harner, T., Hung, H., et al. (2013). The role of the global cryosphere in the fate of organic contaminants. Atmos. Chem. Phys. 13, 3271-3305. doi: 10.5194/acp-13-3271-2013

Grannas, A. M., Jones, A. E., Dibb, J., Ammann, M., Anastasio, C., Beine, H. J., et al. (2007). An overview of snow photochemistry: evidence, mechanisms and impacts. Atmos. Chem. Phys. 7, 4329-4373. doi: 10.5194/acp-7-4329-2007

Gross, G. W., and Svec, R. K. (1997). Effect of ammonium on anion uptake and dielectric relaxation in laboratory-grown ice columns. J. Phys. Chem. B 101, 6282-6284. doi: 10.1021/jp963213c

Hagenmuller, P., Chambon, G., Flin, F., Morin, S., and Naaim, M. (2014). Snow as a granular material: assessment of a new grain segmentation algorithm. Granul. Matter 16, 421-432. doi: 10.1007/s10035-014-0503-7

Hewitt, A. D., Cragin, J. H., and Colbeck, S. C. (1989). "Does snow have ion chromatographic properties?", in: Proceedings of the 46th Annual Eastern Snow Conference, Quebec, 165-171.

Hewitt, A. D., Cragin, J. H., and Colbeck, S. C. (1991). "Effects of crystal metamorphosis on the elution of chemical species from snow," in Proceedings of the 48th Annual Eastern Snow Conference, (Ontario).

Hobbs, P. (1974). Ice Physics. Oxford: Clarendon Press, 837.

Hoog, I., Mitra, S. K., Diehl, K., and Borrmann, S. (2007). Laboratory studies about the interaction of ammonia with ice crystals at temperatures between 0 and $-20^{\circ}$ C. J. Atmos. Chem. 57, 73-84. doi: 10.1007/s10874-007-9063-0

Hörhold, M. W., Laepple, T., Freitag, J., Bigler, M., Fischer, H., and Kipfstuhl, S. (2012). On the impact of impurities on the densification of polar firn. Earth Planet. Sci. Lett. 325-326, 93-99. doi: 10.1016/j.epsl.2011.12.022

Hullar, T., and Anastasio, C. (2016). Direct visualization of solute locations in laboratory ice samples. Cryosphere 10, 2057-2068. doi: 10.5194/tc-10-20572016

Huthwelker, T., Ammann, M., and Peter, T. (2006). The uptake of acidic gases on ice. Chem. Rev. 106, 1375-1444. doi: 10.1021/cr020506v

Kaempfer, T. U., Schneebeli, M., and Sokratov, S. A. (2005). A microstructural approach to model heat transfer in snow. Geophys. Res. Lett. 32, 1-5. doi: 10.1029/2005GL023873

Kahan, T. F., Wren, S. N., and Donaldson, D. J. (2014). A pinch of salt is all it takes: chemistry at the frozen water surface. Acc. Chem. Res. 47, 1587-1594. doi: $10.1021 /$ ar5000715

Kärcher, B., Abbatt, J. P. D., Cox, R. A., Popp, P. J., and Voigt, C. (2009). Trapping of trace gases by growing ice surfaces including surface-saturated adsorption. J. Geophys. Res. 114:D13306. doi: 10.1029/2009JD011857

Kärcher, B., and Basko, M. M. (2004). Trapping of trace gases in growing ice crystals. J. Geophys. Res. Atmos. 109:D22204. doi: 10.1029/2004JD005254

Kaspari, S., Mayewski, P., Kang, S., Sneed, S., Hou, S., Hooke, R., et al. (2007). Reduction in northward incursions of the South Asian monsoon since 1400 
AD inferred from a Mt. Everest ice core. Geophys. Res. Lett. 34:L16701. doi: 10.1029/2007GL030440

Kellerhals, T., Brütsch, S., Sigl, M., Knüsel, S., Gäggeler, H. W., and Schwikowski, M. (2010). Ammonium concentration in ice cores: a new proxy for regional temperature reconstruction? J. Geophys. Res. Atmos. 115:D16123. doi: 10.1029/ 2009JD012603

Kerbrat, M., Huthwelker, T., Gäggeler, H. W., and Ammann, M. (2010). Interaction of nitrous acid with polycrystalline ice: adsorption on the surface and diffusion into the bulk. J. Phys. Chem. C 114, 2208-2219. doi: 10.1021/ jp909535c

Kerbrat, M., Pinzer, B., Huthwelker, T., Gäggeler, H. W., Ammann, M., and Schneebeli, M. (2008). Measuring the specific surface area of snow with X-ray tomography and gas adsorption: comparison and implications for surface smoothness. Atmos. Chem. Phys. 8, 1261-1275. doi: 10.5194/acp-8-12612008

Kong, X., Waldner, A., Orlando, F., Artiglia, L., Huthwelker, T., Ammann, M., et al. (2017). Coexistence of physisorbed and solvated $\mathrm{HCl}$ at warm ice surfaces. J. Phys. Chem. Lett. 8, 4757-4762. doi: 10.1021/acs.jpclett.7b01573

Koop, T., Kapilashrami, A., Molina, L. T., and Molina, M. J. (2000). Phase transitions of sea-salt/water mixtures at low temperatures: implications for ozone chemistry in the polar marine boundary layer. J. Geophys. Res. Atmos. 105, 26393-26402. doi: 10.1029/2000JD900413

Lalonde, J. D., Poulain, A. J., and Amyot, M. (2002). The role of mercury redox reactions in snow on snow-to-air mercury transfer. Environ. Sci. Technol. 36, 174-178. doi: 10.1021/es010786g

Legrand, M., and Mayewski, P. (1997). Glaciochemistry of polar ice cores: a review. Rev. Geophys. 35, 219-243. doi: 10.1029/96RG03527

Lewis, A., Nathoo, J., Reddy, T., Randall, D., Zibi, L., and Jivanji, R. (2010). Novel Technology for Recovery of Water and Solid Salts from Hypersaline Brines: Eutectic Freeze Crystallization. Available at: https://www.coolseparations.nl/wpcontent/uploads/2017/12/A.-Lewis-Novel-Technology-for-Recovery-of-Water -and-Solid-Salts-from-Hypersaline-Brines-1.pdf (Accessed June 11, 2019).

Li, Z., Edwards, R., Mosley-Thompson, E., Wang, F., Dong, Z., You, X., et al. (2006). Seasonal variability of ionic concentrations in surface snow and elution processes in snow-firn packs at the PGPI site on Ürümqi glacier No. 1, eastern Tien Shan, China. Ann. Glaciol. 43, 250-256. doi: 10.3189/ 172756406781812069

Lorius, C., Merlivat, L., and Hagemann, R. (1969). Variation in the mean deuterium content of precipitations in Antarctica. J. Geophys. Res. 74, 7027-7031. doi: 10.1029/JC074i028p07027

Löwe, H., Spiegel, J. K., and Schneebeli, M. (2011). Interfacial and structural relaxations of snow under isothermal conditions. J. Glaciol. 57, 499-510. doi: $10.3189 / 002214311796905569$

Lu, H., McCartney, S. A., and Sadtchenko, V. (2009). H/D exchange kinetics in pure and $\mathrm{HCl}$ doped polycrystalline ice at temperatures near its melting point: structure, chemical transport, and phase transitions at grain boundaries. J. Chem. Phys. 130:054501. doi: 10.1063/1.3039077

Mann, E., Meyer, T., Mitchell, C. P. J., and Wania, F. (2011). Mercury fate in ageing and melting snow: development and testing of a controlled laboratory system. J. Environ. Monit. 13, 2695-2702. doi: 10.1039/clem10297d

Marty, C., and Meister, R. (2012). Long-term snow and weather observations at Weissfluhjoch and its relation to other high-altitude observatories in the Alps. Theor. Appl. Climatol. 110, 573-583. doi: 10.1007/s00704-012-0584-3

Matykiewiczová, N., Klánová, J., and Klán, P. (2007). Photochemical degradation of PCBs in snow. Environ. Sci. Technol. 41, 8308-8314. doi: 10.1021/es0714686

McFall, A. S., Edwards, K. C., and Anastasio, C. (2018). Nitrate photochemistry at the air-ice interface and in other ice reservoirs. Environ. Sci. Technol. 52, 5710-5717. doi: 10.1021/acs.est.8b00095

Melnikov, I. A. (1997). The Arctic Sea Ice Ecosystem. Amsterdam: Gordon and Breach.

Members Epica Community. (2004). Eight glacial cycles from an Antarctic ice core. Nature 429, 623-628. doi: 10.1038/nature02599

Meyer, T., Lei, Y. D., Muradi, I., and Wania, F. (2009a). Organic contaminant release from melting snow. 1. Influence of chemical partitioning. Environ. Sci. Technol. 43, 657-662. doi: 10.1021/es8020217

Meyer, T., Lei, Y. D., Muradi, I., and Wania, F. (2009b). Organic contaminant release from melting snow. 2. Influence of snow pack and melt characteristics. Environ. Sci. Technol. 43, 663-668. doi: 10.1021/es8020233
Meyer, T., Lei, Y. D., and Wania, F. (2011). Transport of polycyclic aromatic hydrocarbons and pesticides during snowmelt within an urban watershed. Water Res. 45, 1147-1156. doi: 10.1016/j.watres.2010.11.004

Meyer, T., and Wania, F. (2008). Organic contaminant amplification during snowmelt. Water Res. 42, 1847-1865. doi: 10.1016/j.watres.2007.12.016

Mosimann, L., Weingartner, E., and Waldvogel, A. (2002). An analysis of accreted drop sizes and mass on rimed snow crystals. J. Atmos. Sci. 51, 1548-1558. doi: 10.1175/1520-04691994051<1548:aaoads<2.0.co;2

Pinzer, B. R., and Schneebeli, M. (2009). Snow metamorphism under alternating temperature gradients: morphology and recrystallization in surface snow. Geophys. Res. Lett. 36:L23503. doi: 10.1029/2009GL039618

Pinzer, B. R., Schneebeli, M., and Kaempfer, T. U. (2012). Vapor flux and recrystallization during dry snow metamorphism under a steady temperature gradient as observed by time-lapse micro-tomography. Cryosphere 6, 1141-1155. doi: 10.5194/tc-6-1141-2012

Plassmann, M. M., Meyer, T., Lei, Y. D., Wania, F., McLachlan, M. S., and Berger, U. (2010). Theoretical and experimental simulation of the fate of semifluorinated n-alkanes during snowmelt. Environ. Sci. Technol. 44, 6692-6697. doi: 10.1021/ es $101562 \mathrm{~W}$

Pratt, K. A., Custard, K. D., Shepson, P. B., Douglas, T. A., Pöhler, D., General, S., et al. (2013). Photochemical production of molecular bromine in Arctic surface snowpacks. Nat. Geosci. 6, 351-356. doi: 10.1038/ngeo 1779

Pruppacher, H. R., and Klett, J. D. (2004). Microphysics of Clouds and Precipitation. Dordrecht: Kluwer Academic Publishers, doi: 10.1007/0-306-48100-6_12

Pruppacher, H. R., and Klett, J. D. (2010). "Cooling of moist air," in Microphysics of Clouds and Precipitation. Atmospheric and Oceanographic Sciences Library, (Dordrecht: Springer), 18, 485-501. doi: 10.1007/978-0-306-48100-0_12

Purdon, F. F., and Slater, V. W. (1946). Aqueous Solution and the Phase Diagram. London: Edward Arnold And Company.

Riche, F., Bartels-Rausch, T., Schreiber, S., Ammann, M., and Schneebeli, M. (2012). Temporal evolution of surface and grain boundary area in artificial ice beads and implications for snow chemistry. J. Glaciol. 58, 815-817. doi: 10.3189/2012JoG12J058

Röthlisberger, R., Hutterli, M. A., Wolff, E. W., Mulvaney, R., Fischer, H., Bigler, M., et al. (2002). Nitrate in Greenland and Antarctic ice cores: a detailed description of post-depositional processes. Ann. Glaciol. 35, 209-216. doi: 10.3189/172756402781817220

Saltzman, E. S. (1995). "Ocean/atmosphere cycling of dimethylsulfide," in Ice Core Studies of Global Biogeochemical Cycles, ed. R. J. Delmas (Berlin: Springer), 65-89. doi: 10.1007/978-3-642-51172-1_4

Schwikowski, M., Brütsch, S., Gäggeler, H. W., and Schotterer, U. (1999). A high-resolution air chemistry record from an Alpine ice core: fiescherhorn glacier, Swiss Alps. J. Geophys. Res. Atmos. 104, 13709-13719. doi: 10.1029/ 1998JD100112

Sokratov, S. A., and Maeno, N. (1997). "Heat and mass transport in snow under a temperature gradient," in Snow Engineering: Recent Advances, eds Izumi, Nakamura, and Sack (Rotterdam: A.A.Balkema), 49-54.

Sokratov, S. A., and Maeno, N. (2000). Effective water vapor diffusion coefficient of snow under a temperature gradient. Water Resour. Res. 36, 1269-1276. doi: 10.1029/2000WR900014

Sommerfeld, R. A., Friedman, I., and Nilles, M. (1987). "The fractionation of natural isotopes during temperature gradient metamorphism of snow," in Seasonal Snowcovers: Physics, Chemistry, Hydrology. NATO ASI Series (Series C: Mathematical and Physical Sciences), Vol. 211, eds H. G. Jones and W. J. Orville-Thomas (Dordrecht: Springer).

Stefan-Kharicha, M., Kharicha, A., Mogeritsch, J., Wu, M., and Ludwig, A. (2018). Review of ammonium chloride-water solution properties. J. Chem. Eng. Data 63, 3170-3183. doi: 10.1021/acs.jced.7b01062

Stichler, W., Schotterer, U., Fröhlich, K., Ginot, P., Kull, C., Gäggeler, H., et al. (2001). Influence of sublimation on stable isotope records recovered from highaltitude glaciers in the tropical Andes. J. Geophys. Res. Atmos. 106, 22613-22620. doi: 10.1029/2001JD900179

Szyrmer, W., and Zawadzki, I. (1997). Biogenic and anthropogenic sources of iceforming nuclei: a review. Bull. Am. Meteorol. Soc. 78, 209-228. doi: 10.1175/ 1520-0477(1997)078<0209:BAASOI>2.0.CO;2

Taillandier, A. S., Dominé, F., Simpson, W. R., Sturm, M., and Douglas, T. A. (2007). Rate of decrease of the specific surface area of dry snow: isothermal 
and temperature gradient conditions. J. Geophys. Res. Earth Surf. 112:F03003. doi: 10.1029/2006JF000514

Thibert, E., and Dominé, F. (1997). Thermodynamics and kinetics of the solid solution of $\mathrm{HCl}$ in ice. J. Phys. Chem. B 101, 3554-3565. doi: 10.1021/jp962115o

Thibert, E., and Dominé, F. (1998). Thermodynamics and kinetics of the solid solution of HNO 3 in ice. J. Phys. Chem. B 102, 4432-4439. doi: 10.1021/ jp980569a

Thomas, D. N., and Dieckmann, G. S. (eds) (2010). Sea Ice, 2nd Edn. Hoboken, NJ: Wiley. doi: 10.1002/9781444317145

Thompson, L. G., Mosley-Thompson, E., Davis, M. E., Zagorodnov, V. S., Howat, I. M., Mikhalenko, V. N., et al. (2013). Annually resolved ice core records of tropical climate variability over the past 1800 years. Science 340, 945-950. doi: $10.1126 /$ science. 1234210

Ullerstam, M., and Abbatt, J. P. D. (2005). Burial of gas-phase HNO3 by growing ice surfaces under tropospheric conditions. Phys. Chem. Chem. Phys. 7, 3596-3600. doi: 10.1039/b507797d

Virkkunen, K., Moore, J. C., Isaksson, E., Pohjola, V., Perämäki, P., Grinsted, A., et al. (2007). Warm summers and ion concentrations in snow: comparison of present day with Medieval Warm Epoch from snow pits and an ice core from Lomonosovfonna, Svalbard. J. Glaciol. 53, 623-634. doi: 10.3189/ 002214307784409388

Voitkovskii, K. F., Golubev, V. N., Sazonov, A. V., and Sokratov, S. A. (1988). Novye dannye o koeffitsiente diffuzii vodyanogo para $\mathrm{v}$ snege [New data on diffusion coefficient of water vapor in snow]. Mater. Glyatsiologicheskikh Issled. Data Glaciol. Stud. 63, 76-81.

Wagenbach, D., Münnich, K. O., Schotterer, U., and Oeschger, H. (1988). The anthropogenic impact on snow chemistry at Colle Gnifetti, Swiss Alps. Ann. Glaciol. 10, 183-187. doi: 10.1017/s0260305500004407

Wagnon, P., Delmas, R. J., and Legrand, M. (1999). Loss of volatile acid species from upper firn layers at Vostok, Antarctica. J. Geophys. Res. Atmos. 104, 3423-3431. doi: 10.1029/98JD02855

Wang, S., Shi, X., Cao, W., and Pu, T. (2018). Seasonal variability and evolution of glaciochemistry at an alpine temperate glacier on the southeastern Tibetan Plateau. Water 10:114. doi: 10.3390/w10020114
Wolff, E. W. (1996). "Location, movement and reactions of impurities in solid ice," in Chemical Exchange Between the Atmosphere and Polar Snow, eds E. W. Wolff and R. C. Bales (Berlin: Springer), 541-560. doi: 10.1007/978-3-64261171-1_23

Workman, E. J., and Reynolds, S. E. (1950). Electrical phenomena occurring during the freezing of dilute aqueous solutions and their possible relationship to thunderstorm electricity. Phys. Rev. 78, 254-259. doi: 10.1103/PhysRev. 78.254

Wu, G., Li, P., Zhang, X., and Zhang, C. (2018). Using a geochemical method of dissolved and insoluble fractions to characterize surface snow melting and major element elution. J. Glaciol. 64, 1003-1013. doi: 10.1017/jog.2 018.87

Yosida, Z., Oura, R., Kurolwa, D., Ruzioka, T., Kojima, K., Aoki, S. I., et al. (1955). Physical studies on deposited snow. 1.: thermal properties. Contrib. Inst. Low Temp. Sci. 7, 19-74.

You, X., Li, Z., Edwards, R., and Wang, L. (2015). The transport of chemical components in homogeneous snowpacks on urumqi glacier no. 1, eastern tianshan mountains, central Asia. J. Arid Land 7, 612-622. doi: 10.1007/s40333015-0131-z

Zimmermann, S., Kippenberger, M., Schuster, G., and Crowley, J. N. (2016). Adsorption isotherms for hydrogen chloride $(\mathrm{HCl})$ on ice surfaces between 190 and 220 K. Phys. Chem. Chem. Phys. 18, 13799-13810. doi: 10.1039/c6cp01962e

Conflict of Interest Statement: The authors declare that the research was conducted in the absence of any commercial or financial relationships that could be construed as a potential conflict of interest.

Copyright (c) 2019 Trachsel, Avak, Edebeli, Schneebeli, Bartels-Rausch, Bruetsch and Eichler. This is an open-access article distributed under the terms of the Creative Commons Attribution License (CC BY). The use, distribution or reproduction in other forums is permitted, provided the original author(s) and the copyright owner(s) are credited and that the original publication in this journal is cited, in accordance with accepted academic practice. No use, distribution or reproduction is permitted which does not comply with these terms. 